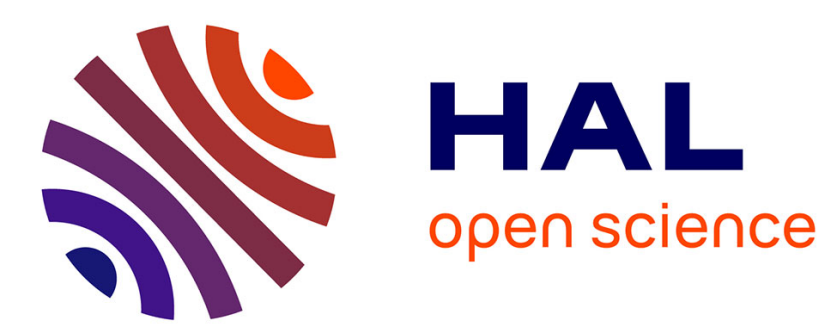

\title{
Consumer confusion over the profusion of eco-labels: lessons from a double differentiation model.
}

\author{
Dorothée Brécard
}

\section{To cite this version:}

Dorothée Brécard. Consumer confusion over the profusion of eco-labels: lessons from a double differentiation model.. 2012. hal-00759260

\author{
HAL Id: hal-00759260 \\ https://hal.science/hal-00759260 \\ Preprint submitted on 30 Nov 2012
}

HAL is a multi-disciplinary open access archive for the deposit and dissemination of scientific research documents, whether they are published or not. The documents may come from teaching and research institutions in France or abroad, or from public or private research centers.
L'archive ouverte pluridisciplinaire HAL, est destinée au dépôt et à la diffusion de documents scientifiques de niveau recherche, publiés ou non, émanant des établissements d'enseignement et de recherche français ou étrangers, des laboratoires publics ou privés. 

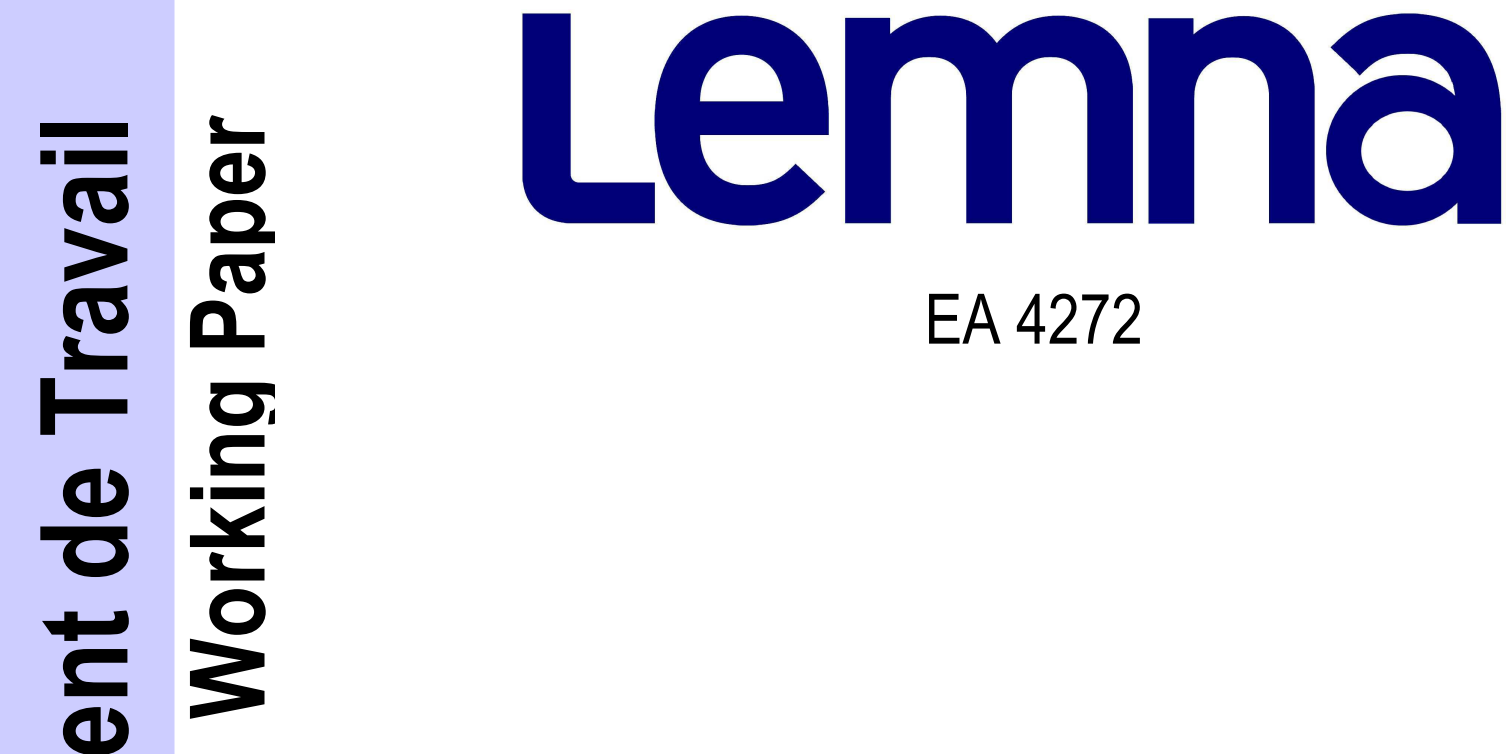

EA 4272

\section{Consumer confusion over the profusion of eco-labels: lessons from a double differentiation model}

\section{Dorothée Brécard*}

$2012 / 46$

* LEMNA, Université de Nantes

Laboratoire d'Economie et de Management Nantes-Atlantique Université de Nantes

Chemin de la Censive du Tertre - BP 52231

44322 Nantes cedex 3 - France

www.univ-nantes.frliemn-iae/recherche

Tél. +33 (0)2 40141717 - Fax +33 (0)2 40141749 


\title{
Consumer confusion over the profusion of eco- labels: lessons from a double differentiation model
}

\author{
Dorothée Brécard
}

Université de Nantes, LEMNA, Institut d'Économie et de Management de Nantes - IAE, Chemin de la Censive du Tertre, BP 52231, 44322 Nantes Cedex 3, France.

Email: dorothee.brecard@univ-nantes.fr, Tel: 332401417 35, Fax: 33240141749

\begin{abstract}
How are eco-label strategies affected by consumer confusion arising from the profusion of eco-labels? This article provides a theoretical insight into this issue using a double differentiation framework. We assume that consumers perceive a label as a sign of quality compared to an unlabeled product, but that they can't distinguish the environmental quality associated with each label. They only perceive each label as a particular variety of the product. We deduce preferences for two types of label: a health label and an eco-label. We analyze pricing strategies of three firms each providing one product: a health labeled, ecolabeled or an unlabeled product. We infer lessons for eco-labeling policies, through effects of ecolabeling on welfare components, according to the identity of the certifying organization: the regulator, who aims at enhancing welfare, an NGO, which attempts to enhance the quality of the environment, and the firms, which seek to maximize their profits. We show that the firm supplying the eco-labeled product is weakened by consumer confusion while the firms selling the unlabeled product suffers from strict labels, to the benefit of the firm supplying the health labeled product. All label policies imply, whatever the certifying organization, high identical environmental quality of the labeled products, which leads to a reduction in the market share of the unlabeled product or even to its extinction.
\end{abstract}

Keywords. Eco-label, environmental quality, green consumer, product differentiation.

JEL classification. D11, D62, D83, L15, Q58 


\section{Introduction}

Ecolabel Index, a global directory, currently identifies 377 eco-labels in 211 countries and 25 industry sectors. ${ }^{1}$ Some labels are rigorously certified by a third-party, such as a public institute or a Non-Governmental Organization (NGO), but others arise from self-declarations by firms, which use more or less stringent certification criteria. An institution can even be behind several environmental labels. For instance, European Commission issues the eco-label Flower, which certifies "products and services that are kinder to the environment" , but also the organic logo, which certifies that " $95 \%$ of the product's ingredients of agricultural origin have been organically produced" 3 . While these environmental labels are indispensable for signaling the environmental quality of credence goods to consumers, the profusion of labels may induce consumer confusion about the real guaranties they provide.

In Europe, for instance, almost half of individuals surveyed by the Gallup Organization state that ecolabeling plays an important role in their purchasing decisions, but $61 \%$ do not know the Flower logo (European Commission, 2009). In the same way, $75 \%$ of Europeans are "ready to buy environmentally friendly products even if they are more expensive" but, paradoxically, $42 \%$ don't think that current labels on products allow them "to identify those products that are genuinely environmentally friendly" (European Commission, 2008). Hence, while environmental labels have a crucial role to play in order to stimulate green consumption, consumers are currently not familiar with them.

There is growing literature dealing with the optimal policies and corporate strategies for eco-labeling in the case of both complete and incomplete information of consumers who care about environmental impact of products. ${ }^{4}$ When information is incomplete, eco-labels lose credibility, as firms may be tempted to develop "greenwashing" strategies in order to benefit from consumers' high willingness-to-pay for green products. Label profusion may reinforce consumer skepticism about their claims. In our analysis, we assume that consumers misperceive the environmental quality of labeled products, believing that all labels signal the same environmental quality. Nevertheless, labels differ from one another by their logos and the message they convey. In this way, consumers perceive labeled products as different varieties of the good.

Most theoretical eco-labeling analysis adopts the differentiation model framework. In vertical product differentiation models, the eco-label signals the low environmental impact of the labeled product compared to the unlabeled products. In line with Mussa and Rosen's framework (1978), these models assume that all consumers are green but differ in their marginal willingness-to-pay for green quality. Accordingly, an increasing degree of environmental awareness of consumers leads to a rising demand for the eco-

\footnotetext{
${ }^{1}$ This directory was initiated in 2009 by Big Room Inc., a Vancouver-based company, and the World Resources Institute, a Washington DC-based environmental think tank (www.ecolabelindex.com, accessed 23/03/2011).

${ }^{2}$ www.ecolabel.eu, accessed 23/03/2011.

${ }^{3}$ ec.europa.eu/agriculture/organic/consumer-confidence/logo-labelling_en, accessed 23/03/2011.

${ }^{4}$ See Amacher et al. (2004), Erikson (2004), Conrad (2005), Ben Youssef and Lahmadi-Ayed (2008) and Clemenz (2010) for analyses of optimal policies in case of complete information, and Mason (2006), Ibanez and Grolleau (2008), Mahenc $(2008,2009)$ and Ben Youssef and Abderrazack (2009) for analysis in cases of incomplete information.
} 
labeled product (Amacher et al., 2004, Ben Youssef and Lahmandi-Ayed, 2008, Ben Youssef and Abderrazack, 2009, Bottega and De Freitas, 2009, Ibanez and Grolleau, 2008, Mahenc, 2008). In horizontal differentiation models, consumers purchase the product closest to their ideal product, which is more or less green according to their tastes. In line with d'Aspremont et al.'s model (1979), consumers gain utility when the difference between their ideal variety and the variety they really consume decreases. By purchasing the eco-labeled product, consumers may be partially conscious of contributing to a better environment (Boyer et al., 2006, Clemenz, 2010, Mahenc, 2009) or feel a warm glow induced by this contribution (Eriksson, 2004, Conrad, 2005). In such a framework, Clemenz (2010) is the only one to introduce a vertical dimension by assuming that willingness-to-pay the environmental quality may be uniformly distributed across consumers. These papers highlight the conditions under which ecolabeling may be an efficient policy, conditions concerning, regading firms, cost structures (Amacher et al., 2004), abatement method (Clemenz, 2010), resistance costs (Ben Youssef and Lahmandi-Ayed, 2008), labeling cost (Ibanez and Grolleau, 2008) and, regarding consumers, environmental consciousness (Erikson, 2004), information (Ben Youssef and Abderrazack, 2009), and the number of altruistic and egoistic consumers in the society (Grolleau et al., 2009).

To the best of our knowledge, the only paper dealing with eco-label profusion is that of Ben Youssef and Abderrazak (2009), who show that "when there is multiplicity of eco-labels, the incentive of each firm is to diminish their respective environmental qualities, and the consumer will not take into account the label in her decision to buy the product." Consequently, the government's role is to attempt to clarify information provided by eco-labels in order to avoid such undesirable effects. Their analysis differs from ours. First, they deal with competition between two labels, whereas we introduce an unlabeled product provided by a third firm. Secondly, they assume that consumers believe that both labels are different but don't know which is the best. In contrast, we assume that consumers believe that both labels signal the same environmental quality, but differ horizontally. In other words, we assume that products are characterized by double differentiation: a vertical feature, related to the presence or not of a label on the good, and a horizontal one, related to the nature of the label when it is stamped on the product.

Indeed, consumers undoubtedly view the label as an indication of quality. All consumers prefer labeled products but they differ in their willingness to pay for them, mainly according to their socio-economic characteristics (Brécard et al., 2009, Schumacher, 2010). Furthermore, consumers are dealing with a credence good. In order to value the quality promoted by the label, they need to be informed about production and consumption issues relating to the good. Accordingly, their quality awareness rises with their confidence in the certifying organization, their level of education and their environmental and/or social involvement (OECD, 2005, Torgler and Garcia-Valiñas, 2007) but also with their degree of perceived personal responsibility in environmental harm (Arkesteijn and Oerlemans, 2005, Ek and Söderholm, 2008) and their degree of altruism (Kotchen and Moore, 2007).

However, labels differ according to their logo and the message they communicate, and can be more environment or health oriented. Consumer's moral and social values determine their ideal label, for which they may need to purchase the nearest substitute in the event of their ideal product not being available. Consumers' values incorporate the 
importance they attach to health and environment. For instance, consumers may be more willing to pay a premium for organic apples than for eco-labeled and regular apples because of the healthier image of organic apples (McCluskey and Loureiro, 2003), whereas they may be more willing to pay a premium for eco-labeled coffee than for organic coffee because coffee is not associated with health (Loureiro and Lotade, 2005). It is worth noting that health and environmental concerns are generally strongly related, as shown in studies dealing with eco-label (Grankvist and Biel, 2001, 2007, Torgler and Garcia-Valiñas, 2007), and that it is not easy to disentangle factors explaining preference for a label over another. However, since consumers are more directly concerned by health than by environmental quality, their preference for an ecolabel instead of a health label can be linked to their degree of altruism (Andreoni, 1990). When those labels are horizontally differentiated, the degree of altruism can be measured by the distance between the ideal label and the health label or the proximity of this ideal with the eco-label. Accordingly, consumers prefer the health labeled product when they have a low degree of altruism, they are very concerned about their health and that of their relatives and they are worried about the health risks of the product. Conversely, they are more likely to be eco-consumers when their degrees of altruism and their environmental consciousness are higher and when they feel highly responsible for environmental damage.

In this article, using an original double differentiation model, we study preferences for two label types: a health label and an eco-label. We analyze the pricing strategies of the three firms providing the unlabeled product, the health labeled product or the ecolabeled product. We deduce eco-labeling policies, through effects of ecolabeling on welfare components, according to the identity of the certifying organization: the regulator, who aims to improve welfare, an $\mathrm{NGO}$, which attempts to improve the quality of the environment, and the firms, who want to maximize their profits.

We show that the firm supplying the eco-labeled product is weakened by consumer confusion, especially when the eco-label is strict. Both firms selling labeled products benefit from a strict health label at the expense of the unlabeled product. All label policies imply, whatever the certifying organization, high identical environmental quality of the labeled products, which leads to an important reduction in the market share of the unlabeled product or even to its extinction. Furthermore, the regulator, the NGO and the green firms had better differentiated the labels, although the environmental quality of both labeled products are the same.

The remainder of the paper is structured as follows. In Section 2, we analyze consumer demand for various products. In Section 3, we study pricing strategies of firms. In Section 4, we analyze labeling strategies according to the certifying organization, and in Section 5 we give our conclusion.

\section{Consumer demand}

Our analysis is based on an extension of Neven and Thisse's (1990) model, where two products are in competition, each one being characterized by a specific quality and variety. We differ from this analysis since horizontal differentiation only concerns labeled products. In other words, only the choice of a labeled product enables the consumer to choose a type of label. This assumption is close to that of Canoy and Peitz (1997), who consider a "differentiation triangle" where variants of low quality cannot 
be horizontally differentiated whereas variants of high quality are horizontally differentiated in the eyes of consumers. The main difference is that, in our model, while labeled products are horizontally differentiated, they can also be vertically differentiated, but consumers cannot perceive the difference in quality.

The consumers' decision tree is depicted in Figure 1. We denote $q_{N L}$ the quality of the unlabeled product and $q_{L}$ the perceived quality of the labeled one, with $q_{i} \in[\underline{q}, \bar{q}]$ ( $i=N L, L)$ and $q_{L} \geq q_{N L}$. Actually, in the case of eco-labels, quality measures the environmental consequences of a product from cradle to grave, whereas, in the case of health labels, it appraises the health consequences of the product during its consumption. However, as consumers do not have such accurate information, we assume that they believe that product quality is the same whatever the label stamped on the product. We denote $l_{H}$ the health label and $l_{E}$ the eco-label spread on linear space $[0,1]$. We assume, without loss of generality, that $l_{H}=0$ and $l_{E}=1$.

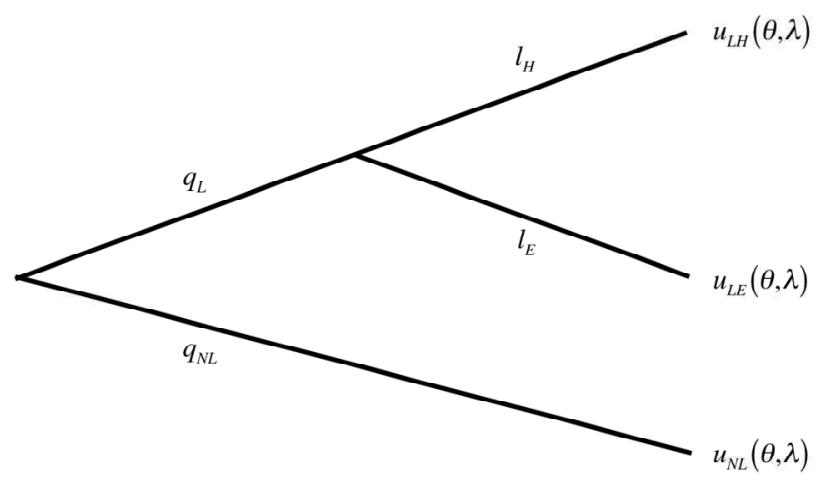

Figure 1. Consumers' decision tree

In line with product differentiation models, we assume that each consumer buys one unit of the product or none. This assumption amounts to considering that the quantity of product to be purchased is fixed or, alternatively, that satisfaction is only gained from the consumption of the first unit of the product. Accordingly, each consumer can only choose between one of the three products or none.

The consumer is characterized by a marginal willingness-to-pay for quality, $\theta$, and an ideal label, $\lambda$. We assume that $\theta$ is uniformly distributed over $[\bar{\theta}-1, \bar{\theta}]$ and $\lambda$ is uniformly distributed over $[0,1]$. Consumers are thus uniformly distributed on the unit square $[\bar{\theta}-1, \bar{\theta}] \times[0,1]$. We suppose that the market is fully covered.

Consumer willingness-to-pay for quality $q_{i}$ is defined by $\theta q_{i}$ and measures the gross surplus of consumer $\theta$ when choosing quality $q_{i}$ of the product. Otherwise, the distance between the ideal label, $\lambda$, and the label of the consumed product tends to reduce the consumer's gross surplus. We assume that this gross surplus decreases from $\tau\left|\lambda-l_{j}\right|$, with $\tau \geq 0$, when label $l_{j}$ is chosen instead of label $\lambda$. In addition, a consumer derives gross utility $r$ from consuming one unit of the product ${ }^{5}$. Consumer preferences are therefore represented by the following utility function:

\footnotetext{
${ }^{5} r$ is assumed sufficiently large to ensure the market is covered.
} 


$$
u_{i j}(\theta, \lambda)=r+\theta q_{i}-\tau_{i}\left|l_{j}-\lambda\right|-p_{i j} \quad i=N L, L \quad j=H, E
$$

with $p_{i j}$ the price of product $i j$ characterized by a quality $q_{i}$ and a label $l_{j}, \tau_{L}=\tau>0$, and $\tau_{N L}=0$.

Lemma 1. Unlabeled and labeled products are vertically differentiated if $(\bar{\theta}-1)\left(q_{L}-q_{N L}\right) \geq \tau$.

If all products were sold at the same price $p$, all consumers would like to purchase a labeled one when condition $\theta\left(q_{L}-q_{N L}\right) \geq \tau\left|l_{j}-\lambda\right|$ is fulfilled for all $\theta, \lambda$ and $l_{j}$. This means that for each consumer, the willingness-to-pay a premium for a labeled product must be higher than the transport cost towards one of the labeled products. Hence, in this case, the utility function increases with quality. This characterizes vertical product differentiation. As a result, each labeled product would benefit from a positive demand. This characterizes horizontal product differentiation.

In order to analyze consumer demand, we define types of consumers who are indifferent towards at least two products. $\hat{\theta}_{j}(\lambda)$ characterizes consumers who are indifferent towards the unlabeled product at price $p_{N L}$ with quality $q_{N L}$ and the labeled product with quality $q_{L}$ and label $l_{j}$ at price $p_{L j}$ :

$$
\hat{\theta}_{j}(\lambda)=\frac{p_{L j}-p_{N L}+\tau\left|\lambda-l_{j}\right|}{q_{L}-q_{N L}}
$$

$\hat{\lambda}$ denotes the type of consumers who are indifferent towards the product labeled $l_{H}$ and the product labeled $l_{E}$. It is defined by:

$$
\hat{\lambda}=\frac{p_{L E}-p_{L H}+\tau}{2 \tau}
$$

$\hat{\theta}(\hat{\lambda})$ typifies the consumer who is indifferent towards all three products:

$\hat{\theta}(\hat{\lambda})=\frac{p_{L H}+p_{L E}-2 p_{N L}+\tau}{2\left(q_{L}-q_{N L}\right)}$

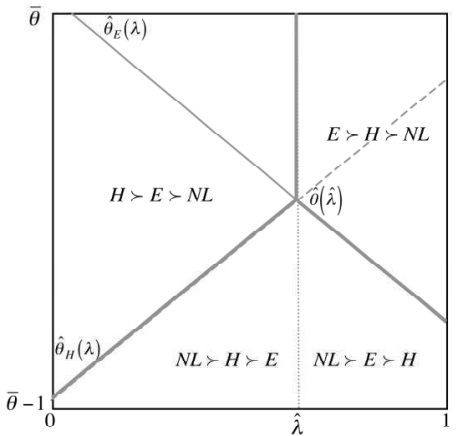

Fig. 2a. Case I

$\hat{\theta}_{H}(0) \geq \bar{\theta}-1$ and $\hat{\theta}_{E}(1) \geq \bar{\theta}-1$

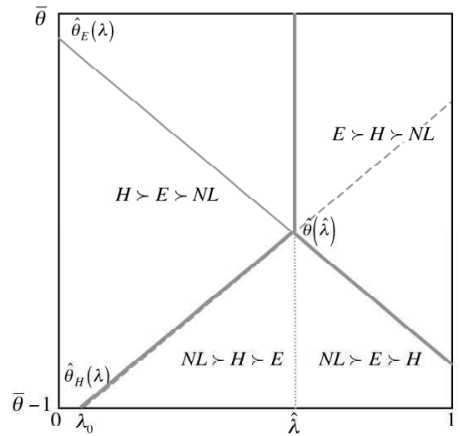

Fig. 2b. Case II

$\hat{\theta}_{H}(0)<\bar{\theta}-1$ and $\hat{\theta}_{E}(1) \geq \bar{\theta}-1$

Figures 2. Consumer space

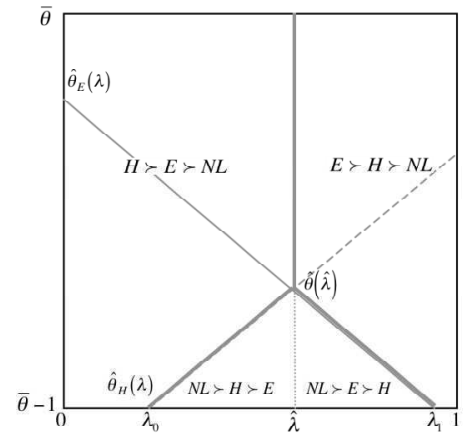

Fig. 2c. Case III $\hat{\theta}_{H}(0)<\bar{\theta}-1$ and $\hat{\theta}_{E}(1)<\bar{\theta}-1$ 
Consumers $\hat{\theta}_{H}(\lambda), \hat{\theta}_{E}(\lambda)$ and $\hat{\lambda}_{H E}$ are represented in the space $(\lambda, \theta)$ in Figures 2 above, with three possible layouts conditioning the definition of the demand functions.

We assume that $\hat{\theta}(\hat{\lambda})$ is in the interval $[\bar{\theta}-1, \bar{\theta}]$ and that $\hat{\lambda}$ is in the interval $[0,1]{ }^{6}$ At the game equilibrium, the gap between prices must then verify $p_{L E}-p_{L H} \in[0, \tau]$. This conditions simply state that, since the eco-label may incur higher production costs than the health label, $p_{L E} \geq p_{L H}$, and that the price difference between both labeled products must be lower than the transportation cost $\tau$ from the eco-label to the health label. Moreover, since the price difference between a labeled product and the unlabeled one may be lower than the lowest willingness-to-pay a premium for quality $q_{L}$ (as in Figures $2 \mathrm{~b}$ and $2 \mathrm{c}$ ), we define $\lambda_{0}$ such as $\hat{\theta}_{H}\left(\lambda_{0}\right)=\bar{\theta}-1$ and $\lambda_{1}$ such as $\hat{\theta}_{E}\left(\lambda_{1}\right)=\bar{\theta}-1$ : $\lambda_{0}=\left[(\bar{\theta}-1)\left(q_{L}-q_{N L}\right)-\left(p_{L H}-p_{N L}\right)\right] / \tau$ and $\lambda_{1}=\left[(\bar{\theta}-1)\left(q_{L}-q_{N L}\right)-\left(p_{L E}-p_{N L}\right)\right] / \tau$.

Consumers of labeled products are characterized by types $\theta(\lambda) \in\left[\hat{\theta}_{j}(\lambda), \bar{\theta}\right]$, such that $u_{N L}(\theta, \lambda) \leq u_{L_{j}}(\theta, \lambda)$. If $\lambda \in[0, \hat{\lambda}]$, then $u_{L_{H}}(\theta, \lambda) \geq u_{L_{E}}(\theta, \lambda)$ and consumer $\theta(\lambda)$ purchases one unit of the health labeled product. Accordingly, the demand for the health labeled product is represented in Figures 2 by the area above line $\hat{\theta}_{H}(\lambda)$ to the left of the vertical $\lambda=\hat{\lambda}$. Hence, it is defined by: ${ }^{7}$

$$
\begin{aligned}
& d_{L H}^{I}=\frac{p_{L E}-p_{L H}+\tau}{8 \tau\left(q_{L}-q_{N L}\right)}\left(4 \bar{\theta}\left(q_{L}-q_{N L}\right)-p_{L E}-3 p_{L H}+4 p_{N L}-\tau\right) \text { if } \lambda_{0} \leq 0 \\
& d_{L H}^{I I}=\frac{\left(p_{L E}-p_{L H}+\tau\right)}{2 \tau}-\frac{\left(2(\bar{\theta}-1)\left(q_{L}-q_{N L}\right)-p_{L E}-p_{L H}+2 p_{N L}-\tau\right)^{2}}{8 \tau\left(q_{L}-q_{N L}\right)} \text { otherwise }
\end{aligned}
$$

Consumers of the eco-labeled product have types $\lambda \in\left[\hat{\lambda}_{H E}, 1\right]$, such that $u_{L_{F}}(\theta, \lambda) \geq u_{L_{H}}(\theta, \lambda)$. The green demand is depicted in Figures 2 by the area above line $\hat{\theta}_{H}(\lambda)$, to the right of the vertical $\lambda=\hat{\lambda}$. It is thus defined by: ${ }^{8}$

${ }^{6}$ At the game equilibrium, we can show that $\hat{\theta}(\hat{\lambda})$ is always lower than $\bar{\theta}$. Indeed, the contrary case requires that $\frac{p_{L H}+p_{L E}}{2}-p_{N L} \geq \bar{\theta}\left(q_{L}-q_{N L}\right)-\frac{\tau}{2}$. This means that the difference between the average price of the labeled products and the price of the unlabeled product does exceed the willingness-to-pay a premium for the labeled quality of consumer with $(\bar{\theta}, 1 / 2)$, i.e. the average willingness-to-pay a premium for the labeled product of consumers with the highest willingness-to-pay quality. However, at the equilibrium, it is never profitable for the firms to sell their labeled products at a price so much more expensive than the unlabeled product.

7 It is defined by $d_{L H}^{I}=\left[\bar{\theta}-\frac{1}{2} \hat{\theta}_{H}(\hat{\lambda})-\frac{1}{2} \hat{\theta}_{H}(0)\right] \hat{\lambda} \quad$ if $\quad \hat{\theta}_{h}(0) \geq \bar{\theta}-1 \quad$ and $\quad$ by $d_{L H}^{I I}=\hat{\lambda}-\frac{1}{2}\left(\hat{\lambda}-\lambda_{0}\right)\left[\hat{\theta}_{H}(\hat{\lambda})-\bar{\theta}+1\right]$ otherwise

8 It is defined by $d_{L E}^{I}=\left[\bar{\theta}-\frac{1}{2} \hat{\theta}_{E}(\hat{\lambda})-\frac{1}{2} \hat{\theta}_{E}(1)\right] \hat{\lambda} \quad$ if $\quad \hat{\theta}_{h}(0) \geq \bar{\theta}-1 \quad$ and by $d_{L E}^{I I}=(1-\hat{\lambda})-\frac{1}{2}\left(\lambda_{1}-\hat{\lambda}\right)\left[\hat{\theta}_{H}(\hat{\lambda})-\bar{\theta}+1\right]$ otherwise. 


$$
\begin{aligned}
& d_{L E}^{I}=\frac{\tau-p_{L E}+p_{L H}}{8 \tau\left(q_{L}-q_{N L}\right)}\left(4 \bar{\theta}\left(q_{L}-q_{N L}\right)-3 p_{L E}-p_{L H}+4 p_{N L}-\tau\right) \text { if } \lambda_{1} \geq 1 \\
& d_{L E}^{I I}=\frac{\tau-p_{L E}+p_{L H}}{2 \tau}-\frac{\left(2(\bar{\theta}-1)\left(q_{L}-q_{N L}\right)-p_{L E}-p_{L H}+2 p_{N L}-\tau\right)^{2}}{8 \tau\left(q_{L}-q_{N L}\right)} \text { otherwise }
\end{aligned}
$$

Consumers of the unlabeled product are characterized by types $\theta(\lambda) \in\left[\bar{\theta}-1, \hat{\theta}_{j}(\lambda)\right]$, such that $u_{L j}(\theta, \lambda) \leq u_{N L}(\theta, \lambda)$. The demand for the unlabeled product is simply defined by:

$$
d_{N L}=1-d_{L H}-d_{L E}
$$

with $d_{L j}=d_{L j}^{I}$ or $d_{L j}^{I I}$, depending on the values of $\lambda_{0}$ and $\lambda_{1}$. In Figures 2 , it corresponds to the area below both lines $\hat{\theta}_{H}(\lambda)$ and $\hat{\theta}_{E}(\lambda)$.

Demand analysis emphasizes that a consumer is more likely to buy a labeled product, since his marginal willingness-to-pay for quality, $\theta$, is high, quality $q_{L}$ of the labeled products is high and the price premiums of the labeled products are low, there exists a label close to his ideal label, $\lambda$, and/or his disutility $\tau$ from deviating from his ideal label is low.

\section{Firm strategies}

The competition between firms takes place in a two-stage game. In the first stage, the quality to be produced is decided. It is well known that, as quality is costly, a firm firstly chooses either the worst quality $q$ or the minimum standard required for stamping a label on its product, $q_{L H}$ or $q_{L E}$. In the second stage, prices are chosen. We assume that only one firm produces one variant of a product. ${ }^{9}$ A firm has an interest in selecting a variety that differs from those of its competitors, in order to avoid a price war, which would lead to a dramatic fall in profit. It also chooses on its variant among the three variants possible: unlabeled, health labeled or eco-labeled. The latter require providing a quality higher than $q_{L H}$ and $q_{L E}$.

The firm unit production costs are assumed to linearly increase with quality. Their profits are thus defined by:

$$
\pi_{i}=\left(p_{i}-q_{i}\right) d_{i}-k_{i} \quad i=N L, L H, L E
$$

where $k_{i} \geq 0$ is a fixed cost, including the certifying cost. We will consider two cases. In the symmetric case, we assume that qualities are the same whatever the label is. In the asymmetric case, we assume that the eco-labeled product is of better quality than the health labeled one, that is $q_{L E}>q_{L H}$. This assumption is justified by the fact that ecolabeling requires standard commitment along the entire product cycle, whereas health labeling only requires the absence of harmful substances in the product.

\footnotetext{
${ }^{9}$ Canoy and Peitz (1997) show, in a similar framework, that two types of scenario can emerge at the equilibrium: either only two firms decide to produce the good and one of them supplies two products (one high-quality product and one low-quality product) while the other firm supplies the other high-quality product, or three single-product firms enter in the market and supply the three varieties. We restrict our analysis to the latter case, which requires that the fixed cost of the multiproduct firm is higher than the fixed cost of a firm providing only a high-quality product.
} 


\subsection{The symmetric equilibrium}

In the symmetric equilibrium, both labels require the same minimal product standard, denoted $q_{L}$, and consumers assess correctly the quality of both labeled products. Since firms producing labeled products incur the same production cost, they have to sell the good at the same price and consumer demand for labeled product splits equally into both labeled products. Accordingly, market shares of the three firms will crucially depend on highest marginal willingness to pay $\bar{\theta}$, perceived quality $q_{L}$ of the labeled products, quality $\underline{q}$ of the unlabeled product and transport cost $\tau$.

In the second stage, firms compete on price knowing the product qualities decided in the first stage. We have to distinguish two cases, according to the size of the price premium $p_{L}-p_{N L}$ with respect to the lowest willingness to pay the premium for a better quality $(\bar{\theta}-1)\left(q_{L}-\underline{q}\right)$.

In the first case, $p_{L}-p_{N L} \geq(\bar{\theta}-1)\left(q_{L}-\underline{q}\right)$ and the demand functions are defined by $d_{L H}^{I}$ and $d_{L E}^{I}$. Maximization of the profit (8) with respect to price leads to first order conditions (A1) and (A2) in Appendix A1. The unique Nash equilibrium is defined as follows:

$$
\begin{aligned}
& p_{N L}^{I}=q_{L}+\frac{11 \tau-4 \bar{\theta} \Delta q-\phi}{16} \\
& p_{L}^{I}=q_{L}+\tau+\frac{\tau+4 \bar{\theta} \Delta q-\phi}{8}
\end{aligned}
$$

With $\Delta q=q_{L}-q$ and $\phi=\sqrt{97 \tau^{2}+8 \tau \bar{\theta} \Delta q+16 \bar{\theta}^{2} \Delta q^{2}}$. This equilibrium requires that the marginal willingness-to-pay $\bar{\theta}$ is lower than the following threshold $\bar{\theta}_{0}$ :

$$
\bar{\theta}_{0}=\left(16 \Delta q^{2}+14 \tau \Delta q-3 \tau^{2}\right) /(4 \Delta q(2 \Delta q+\tau))
$$

In the second case, $p_{L}-p_{N L}<(\bar{\theta}-1)\left(q_{L}-\underline{q}\right)$ and demands are $d_{L H}^{I I}$ and $d_{L E}^{I I}$. First order conditions (A5) and (A6) in Appendix A1 lead to a unique Nash equilibrium defined by:

$$
\begin{aligned}
& p_{N L}^{I I}=q_{L}+\frac{\tau-(2 \bar{\theta}+19) \Delta q-\psi}{20} \\
& p_{L}^{I I}=q_{L}+\tau+\frac{-27 \tau-(37-14 \bar{\theta}) \Delta q+3 \psi}{20}
\end{aligned}
$$

With $\psi=\sqrt{\tau^{2}-2 \tau(2 \bar{\theta}-31) \Delta q+\left(4 \bar{\theta}^{2}-44 \bar{\theta}+81\right) \Delta q^{2}}$. This equilibrium requires that $\bar{\theta} \geq \bar{\theta}_{0}$.

Note that the price of both labeled products resulting from a simple horizontal differentiation would be $p_{L}^{h}=q_{L}+\tau$. Accordingly, since the third term of equations (10) and (13) are always negative when $(\bar{\theta}-1) \Delta q \geq \tau$, the price of the labeled product is lower when an unlabeled, less expensive, product is available in the market. In the same way, in a model of pure vertical differentiation, with one labeled and one unlabeled product, prices would be $p_{L}^{v}=q_{L}+\bar{\theta} \Delta q / 3$ and $p_{N L}^{v}=q_{L}-\bar{\theta} \Delta q / 3$. Whereas $p_{L}^{v}$ is higher than the price of the labeled products, $p_{N L}^{v}$ may be higher or lower according to the 
values of $\bar{\theta}, \Delta q$ and $\tau .{ }^{10}$ Hence, the competition of a third product unsurprisingly leads to a fall in the price of the labeled product. Furthermore, we can show that the higher $\bar{\theta}$ or $\Delta q$ are, the higher the price of the labeled products will be. Conversely, the price of the unlabeled product tends to decrease with $\bar{\theta}$ and it can slightly increase with $\Delta q$ before decreasing with $\Delta q$. Finally, a high transportation cost $\tau$ weighs on all prices.

The demand for the labeled product is defined by:

$$
\begin{aligned}
& d_{L}^{I}=\frac{\phi+4 \bar{\theta} \Delta q-11 \tau}{32 \Delta q} \\
& d_{L}^{I I}=\frac{1}{2}-\frac{\psi+(1-2 \bar{\theta}) \Delta q+\tau}{200 \tau \Delta q}
\end{aligned}
$$

Each labeled product benefits from a positive demand $d_{L}^{I}$ when $\bar{\theta} \Delta q>\tau / 4$, condition which is fulfilled according to Lemma 1 . It benefits from high willingness-to-pay $\bar{\theta}$ and quality difference $\Delta q$ but it suffers from high transportation cost $\tau$. As a consequence, the unlabeled product remains in the market when $\bar{\theta}$ and $\Delta q$ are not too high and $\tau$ is not too low. ${ }^{11}$

Finally, profit of the firm providing the unlabeled product decreases with $\bar{\theta}$ and $\Delta q$ and increases with $\tau$. Profit of the firms selling the labeled products rises with $\bar{\theta}$ and $\tau$. These firms benefit from high quality $q_{L}$ in spite of their high cost because this favors the demand for labeled products. Therefore, they benefit from labels guaranteeing high quality, when consumers perceive the true quality $q_{L}$. The best situation for them would be a minimum standard $q_{L}$ ousting the unlabeled product and leading to a Hotelling competition between both firms having the labels. In this case, they would equally share the market and earn a profit $\tau / 2$ higher than in a triopoly situation.

\subsection{The asymmetric equilibrium}

In the asymmetric game, firms supplying labeled products differ in the real quality of their products. In other words, the minimum standard is less stringent for the health label than for the eco-label. This leads to a quality of the eco-labeled product $q_{L E}$ that is higher than that of the health labeled product $q_{L H}$. The extent of firm asymmetry is measured by $\gamma \equiv q_{L E} / q_{L H}$, with $\gamma \geq 1$. However, consumers believe that both qualities are the same. We assume that the perceived quality is $q_{L} \equiv \mu q_{L E}+(1-\mu) q_{L H}$, with $0 \leq \mu \leq 1$. In other words, consumers generally overestimate the quality of the health labeled product and underestimate the quality of the eco-labeled product. We call Firm $\mathrm{U}$ the firm supplying the unlabeled product, Firm $\mathrm{H}$ the firm supplying the health labeled product and Firm $\mathrm{E}$ the firm supplying the eco-labeled product.

The equilibrium prices cannot be analytically expressed through first order conditions. We therefore turn to numerical simulations (see Appendix A2). We start

\footnotetext{
${ }^{10}$ Demonstrations can be obtained on request from the author.

${ }^{11}$ Since expressions of demand are not easily handled, we use simulations with various suitable values of $\bar{\theta}, \Delta q$ and $\tau$ in order to assess the effects of parameters on demand. Furthermore, it can be shown that $d_{N L}^{I I}$ tends towards zero when $2(\bar{\theta}-2) \Delta q$ rises to $3 \tau$.
} 
with a central (symmetric) scenario where parameters are set as follows: $\bar{\theta}=2, \tau=1$, $q_{N L}=1, q_{L H}=2, \gamma=1, \mu=1 / 2$ and $k_{i}=0$ for $i=N L, L E, L H .{ }^{12}$ In this central scenario, equilibrium prices are $p_{N L}^{*}=1.356, p_{L H}^{*}=p_{L E}^{*}=2.462$, market shares are $d_{N L}^{*}=0.356$ and $d_{L H}^{*}=d_{L E}^{*}=0.322$, and profits are $\pi_{N L}^{*}=0.127, \pi_{L H}^{*}=\pi_{L E}^{*}=0.149$. Then, we simulate variations in parameters $\bar{\theta}, q_{L}, \gamma$, and $\tau$ of the game. Figures 3 to 6 bring together graphs illustrating their effects on prices, demands and profits. The effects of variations in $\mu$ are relegated in Figures A1 in Appendix A4.

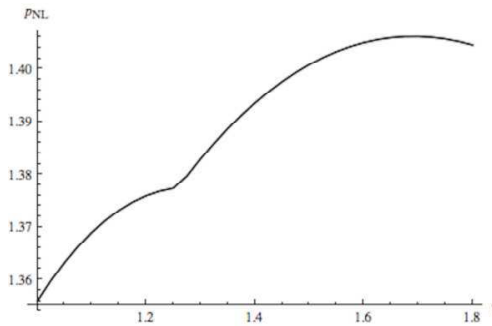

Fig. 3a. $p_{N L}$

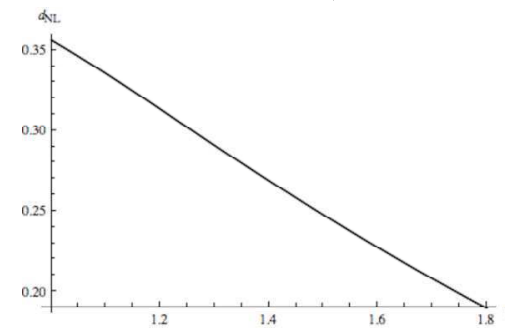

Fig. 3d. $d_{N L}$

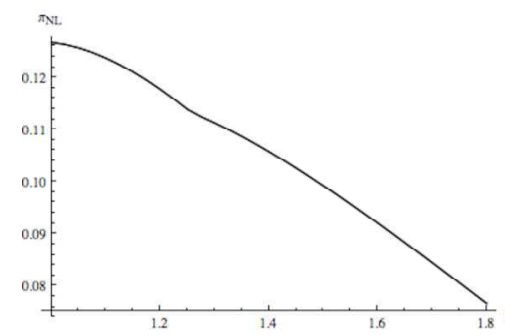

Fig. $3 g . \pi_{N L}$

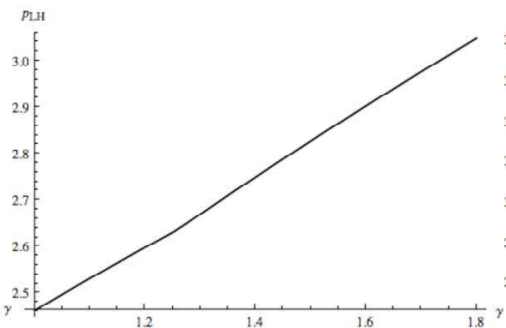

Fig. 3b. $p_{L H}$

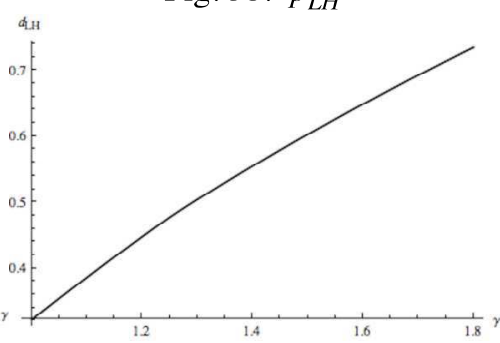

Fig. 3e. $d_{L H}$

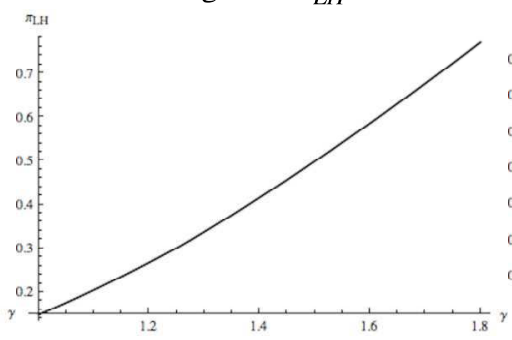

Fig 3 h. $\pi_{L H}$

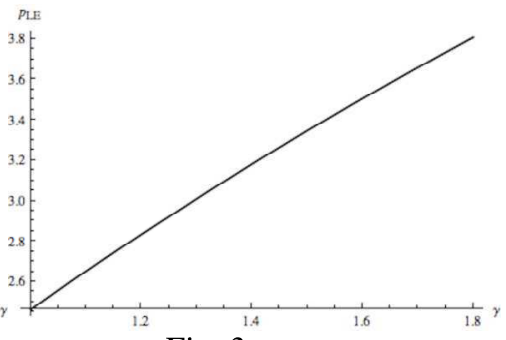

Fig. 3c. $p_{L E}$

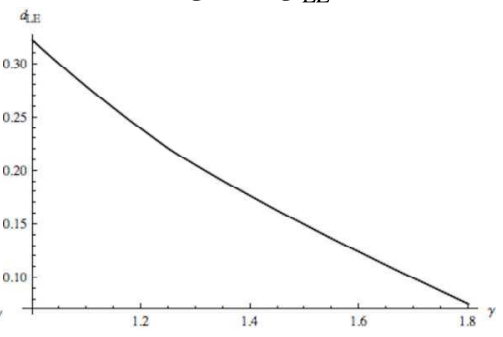

Fig. 3f. $d_{L E}$

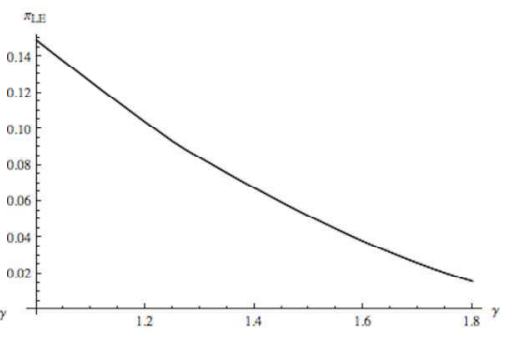

Fig 3i. $\pi_{L E}$

Figures 3. Effects of a rise in quality gap $\gamma$

First, we study a rise in firm asymmetry, $\gamma$. According to Figures 3 , a better quality of the eco-labeled product leads to an increase in prices of both labeled products and it has a bell-shaped effect on the price of the unlabeled product. A deeper analysis shows that relative price $p_{L E} / p_{L H}$ and $p_{L H} / p_{N L}$ increase. Thus, quality improvement harms firm E. It is important to remember that higher quality is not correctly perceived by consumers. As a consequence, firm $\mathrm{E}$ suffers from a loss in its competitiveness with regard to firm $\mathrm{H}$. Thereby, some consumers turn away from the eco-labeled product to the health labeled product ( $\hat{\lambda}$ moves toward the right) or to the unlabeled product $\left(\hat{\theta}_{E}(\lambda)\right.$ moves towards the top). Meanwhile, some consumers turn away from the unlabeled product to the health labeled product $\left(\hat{\theta}_{H}(\lambda)\right.$ moves towards the bottom). The impact on the demand for the unlabeled product depends on the value of $\mu$ : when the

\footnotetext{
${ }^{12}$ In that case, the conditions of Lemma 1 is fulfilled, $\hat{\theta}_{H}(0)>\bar{\theta}-1$ and $\hat{\theta}_{E}(1)>\bar{\theta}-1$ (case I)
} 
perceived quality is significatively higher than $q_{L H}{ }^{13}$, in particular when $\mu=1 / 2$, a higher $\gamma$ tends to reduce $d_{N L}$, whereas the effect is bell-shaped for lower $\mu$. As a consequence, firm $\mathrm{H}$ benefits from a slight increase in $\gamma$ : it can raise its price while still attracting new consumers. Finally, firm E chooses to not enter in the market if the quality gap is higher than the threshold $\bar{\gamma}=1.8$ in our scenario.

We now study the effects of other parameters assuming that the eco-label requires a minimal quality $20 \%$ higher than the health label $(\gamma=1.2)$.

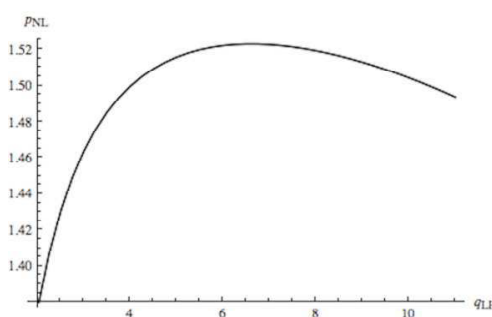

Fig. 4a. $p_{N L}$

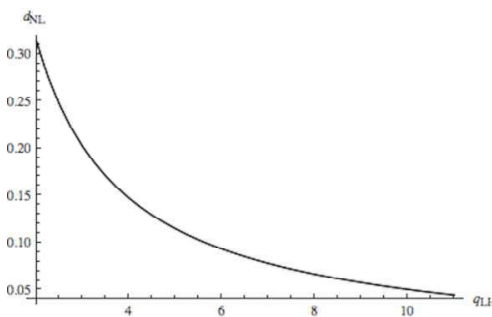

Fig. 4d. $d_{N L}$

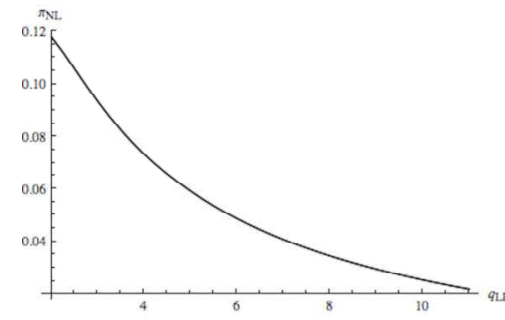

Fig. 4 g. $\pi_{N L}$

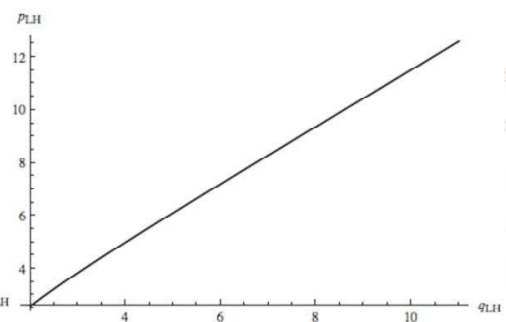

Fig. 4 b. $p_{L H}$

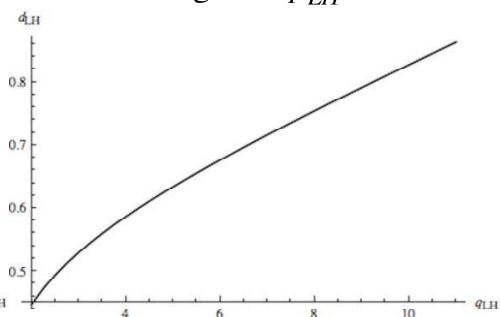

Fig. 4 e. $d_{L H}$

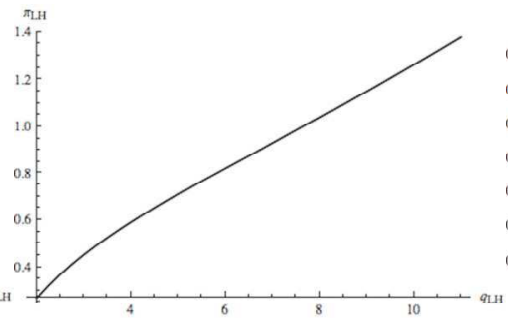

Fig 4 h. $\pi_{L H}$

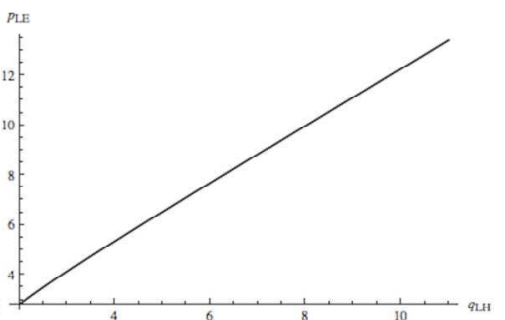

Fig. 4c. $p_{L E}$

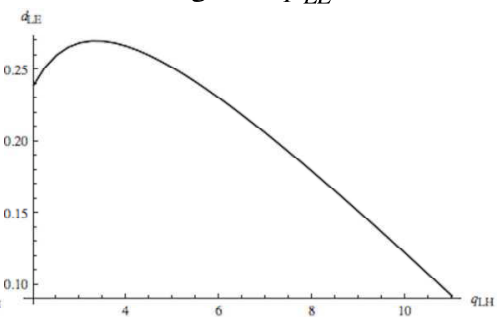

Fig. 4f. $d_{L E}$

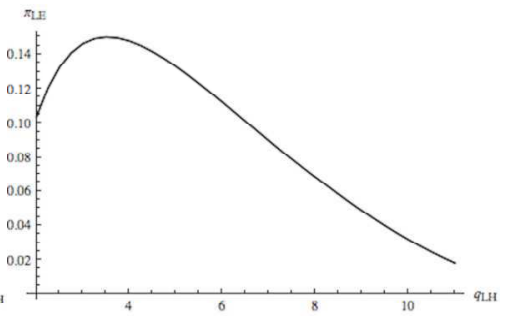

Fig 4 i. $\pi_{L E}$

Figures 4. Effects of a rise in minimum quality standard $q_{L H}$

Figures 4 show the effects of a rise in $q_{L H}$, the volontary minimum quality standard required for health labeling. Weighing on marginal production costs of both labeled product firms, a higher standard pulls prices up. Only firm $\mathrm{H}$ always benefits from this change. Hence, its market share increases at the expense of firm $U$ and also of firm $\mathrm{E}$ when $q_{L H}$ is higher than a given threshold (3.3 in our scenario). Firm E also benefits from a more stringent standard as long as $q_{L H}$ remains lower than a threshold (3.4 in our scenario). Obviously, firm U loses some customers and suffers from a fall in its profit when $q_{L H}$ increases.

\footnotetext{
${ }^{13}$ For $\mu \geq 1 / 3$ in our central scenario.
} 


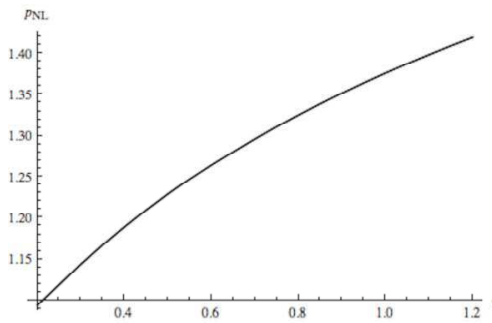

Fig. 5a. $p_{N L}$

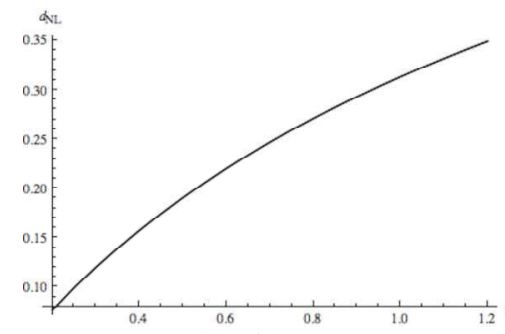

Fig. 5d. $d_{N L}$

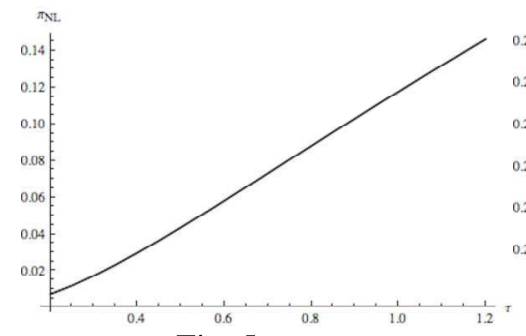

Fig. 5 g. $\pi_{N L}$

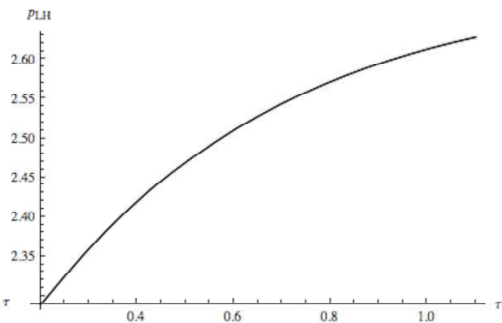

Fig. 5b. $p_{L H}$

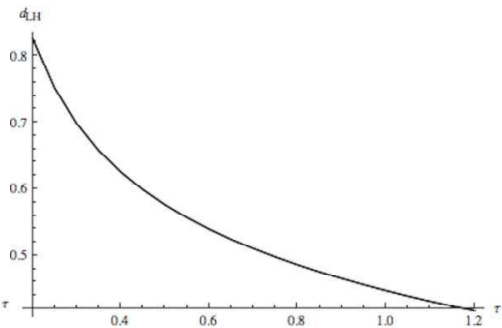

Fig. 5e. $d_{L H}$

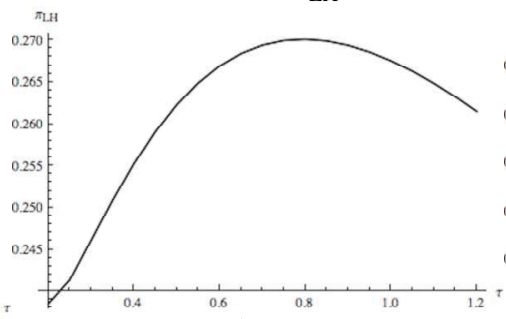

Fig 5 h. $\pi_{L H}$

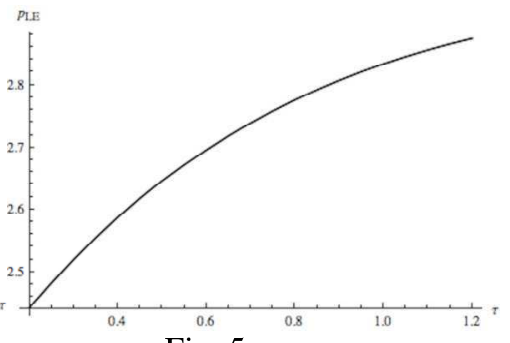

Fig. 5c. $p_{L E}$

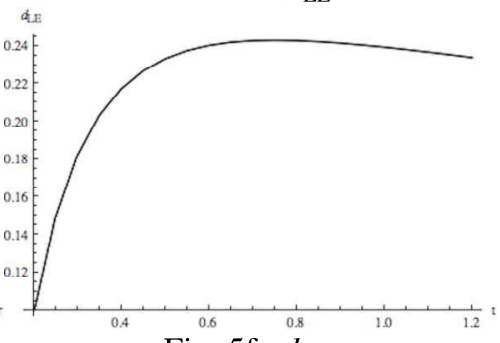

Fig. 5f. $d_{L E}$

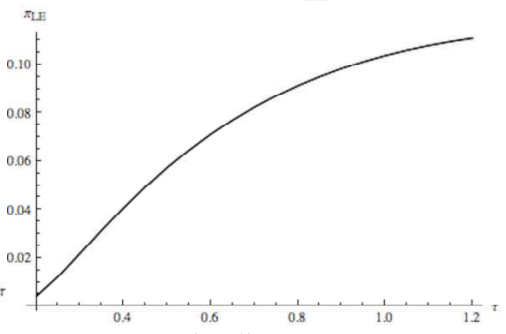

Fig 5i. $\pi_{L E}$

Figures 5. Effects of a rise in transportation $\operatorname{cost} \tau$

According to Figures 5, when consumers' disutility, or transportation cost, $\tau$, of the distance to their most preferred quality varies from 0.2 to $1.2,{ }^{14}$ all prices tend to grow. More precisely, the price of the eco-labeled product increases faster than that of the health-labeled product. Meanwhile, the gap between the prices of labeled products and that of the unlabeled product tends to increase and then to decrease when $\tau$ tends to 1.2. A high transportation cost favors demand for the unlabeled product, but also demand for the eco-labeled product when $\tau$ is lower than 0.75 . Conversely, it harms demand for the health labeled product and demand for the eco-labeled product when $\tau$ is higher than 0.75. All firms yield higher profits for higher $\tau$, except Firm $H$ of which the profit decreases for $\tau$ higher than 0.8 .

According to Figures 6, a rise in marginal willingness-to-pay for quality leads unsurprisingly to a rise in the prices of the labeled products and a fall in the price of the unlabeled product. It tends to divert consumers from the unlabeled product to the benefit of the labeled products. Thereby, the profit of firm $U$ tends to fall while the profits of firms $\mathrm{H}$ and $\mathrm{E}$ tend to increase.

${ }^{14}$ In that case, condition $(\bar{\theta}-1) q_{L} \geq \tau$ of Lemma 1 remains fulfilled. For $\tau<0.2$, Firm $\mathrm{U}$ is ousted from the market in our scenario. It is worth noting that almost all consumers purchase the health labeled product when $\tau$ is close to 0.2 . 


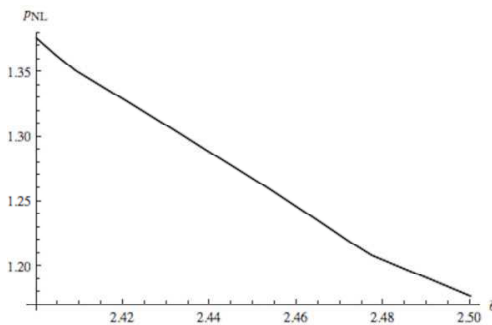

Fig. 6a. $p_{N L}$

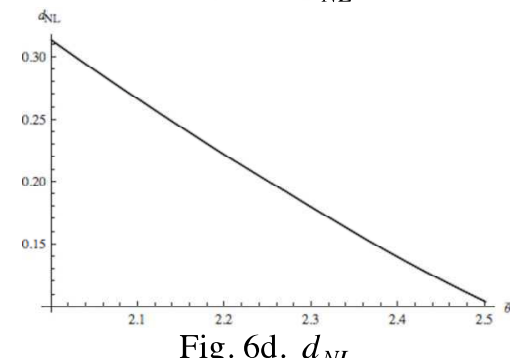

Fig. 6d. $d_{N L}$

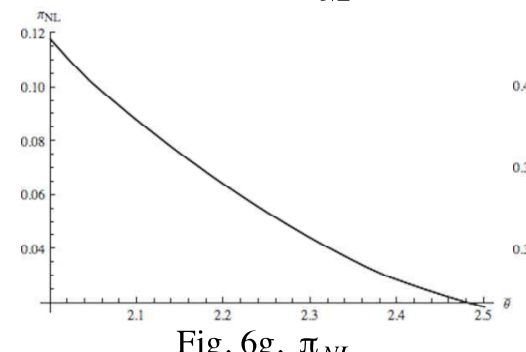

Fig. 6g. $\pi_{N L}$

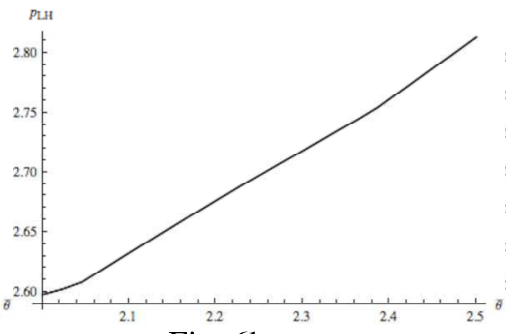

Fig. 6b. $p_{L H}$

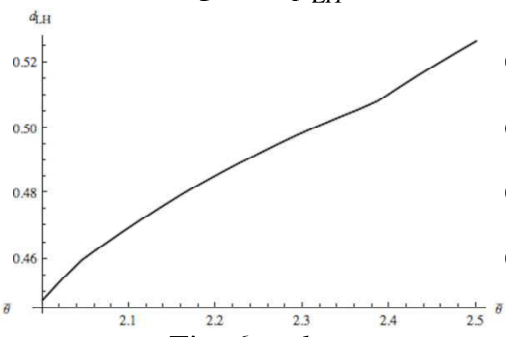

Fig. 6e. $d_{L H}^{2.3}$

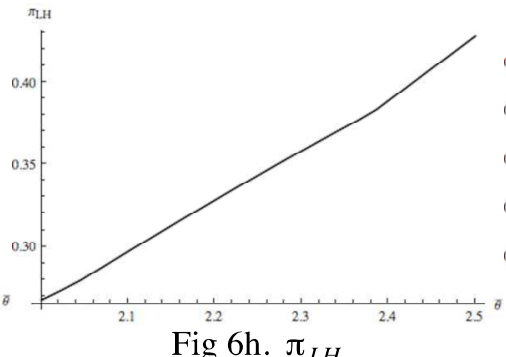

Fig 6 h. $\pi_{L H}$

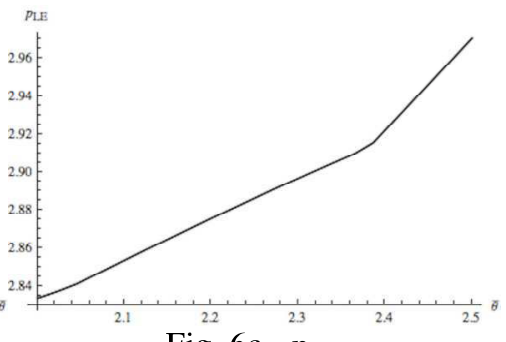

Fig. 6c. $p_{L E}$

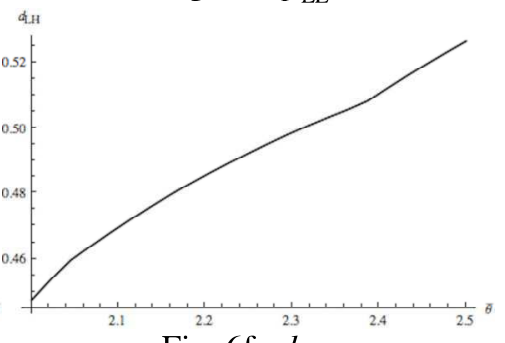

Fig. 6f. $d_{L E}$

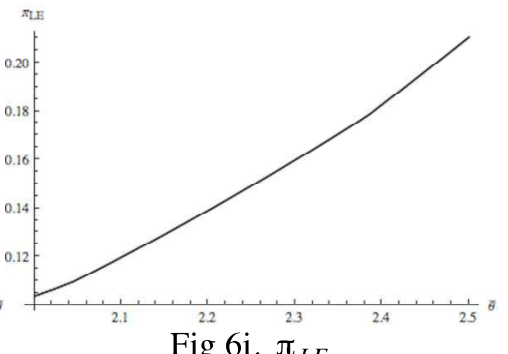

Fig 6i. $\pi_{L E}$

Figures 6. Effects of a rise in willingness-to pay $\bar{\theta}$

The stringency of the eco-label can discourage production of an ecolabeled product while favoring production of the health label product and even that of the unlabeled product. Hence, as in Akerlof's "market for lemons", the bad quality could drive out the good in the market. We thus study more deeply eco-labeling policies in the next section.

\section{Eco-labeling policy}

In this section, we study the effect of labeling in order to analyze the best environmental quality choice according to the instigator of the labels. Whereas public labeling aims to improve welfare, NGO labeling attempts to improve the quality of the environment, and firm labeling only seeks to maximize profit. In other words, using the International Standards Organisation's terminology, we are dealing with type I or type II labels. Type I eco-labels are the most exacting, since they are issued by a third party, basing on the product's life cycle impacts. The European Flower and, more generally, public eco-labels belong to this category. Type II eco-labels arise from self-declarations by firms. Their criteria can differ from one label to another, especially from an NGO label to a firm label. We successively study labeling strategies of firms, an NGO and the regulator when they are in charge of labels. ${ }^{15}$

\footnotetext{
${ }^{15}$ We neglect the certifying cost in the analysis.
} 


\subsection{Private labels}

Firm labeling strategy can easily be deduced from section 3. Remember that consumers wrongly believe that both labeled products have the same quality $q_{L}$ and that the eco-labeled product is only a variant of the labeled good. Consequently, firm $\mathrm{H}$ is the biggest label winner.

Indeed, firm H's profit increases with the minimum quality standard $q_{L H}$ and with quality gap $\gamma$. Firm E's profit grows with $q_{L H}$ as long as $q_{L H}$ remains lower than a certain threshold $\bar{q}_{L H}$, but decreases with $\gamma$. Firm $\mathrm{E}$ is thus better off when it chooses to produce the same quality as firm $\mathrm{H}$ while stamping an eco-label on its product in order to benefit from the taste heterogeneity of consumers. Accordingly, quality strategies of firms $\mathrm{H}$ and $\mathrm{E}$ lead to the symetric equilibrium.

Since symetric firms' profit increases with quality $q_{L}$ whereas firm U's profit decreases, firms $\mathrm{H}$ and $\mathrm{E}$ maximize their profit by choosing quality $q_{L}^{*}$ that drives firm $\mathrm{U}$ out, if $q_{L}^{*} \leq \bar{q}$, and quality $\bar{q}$ otherwise. Using equation (14), we can define the optimal quality of the labeled product as follows:

$$
q_{L}^{*}=\underline{q}+\frac{3 \tau}{2(\bar{\theta}-2)}
$$

$q_{L}^{*}$ is defined for $\bar{\theta}>2$. It linearly increases with $\tau$ and convexly decreases with $\bar{\theta}$. Price competition between the duopoly in the horizontally differentiated market leads to an equilibrium pricing $\tau+q_{L}^{*}$ and to an equitable sharing of demand.

By underestimating the quality of the eco-labeled product, consumers limit their willingness to pay for this product. This prevents firm E from selling its eco-labeled product more expensively than the health-labeled product even if its marginal production cost is higher than that of firm $\mathrm{H}$. As a consequence, firm $\mathrm{E}$ has nothing better to do but supply the same product as its competitor, while displaying a different label praising its environmental friendliness. Thus, consumer confusion over the profusion of labels triggers fierce competition not only between labeled and unlabeled products, labels being used as an exclusionary strategy of the unlabeled product, but also between both labels. This entails a kind of green washing strategy of firm E. ${ }^{16}$

\subsection{NGO's labels}

By proposing both a health label and an eco-label, the NGO attempts to minimize pollution. Pollution cannot be reduced through a fall in global demand, since the market is fully covered and the total demand is always equal to one. However, pollution can be lowered through a better distribution of the consumption of the three products. The lowest pollution would obviously be obtained when all consumers buy the eco-labeled product from the greenest firm. A second best situation would be the distribution of the consumption between both labeled products. In other words, from the perspective of the NGO, the unlabeled product should disappear from the market.

${ }^{16}$ It is worth noting that if consumers underestimate the quality of the health-labeled product and overestimate the quality of the eco-labeled product, strategies would be symmetric: Firm H would stamp a label praising the beneficial effects of the product on health, whereas the product would also be beneficial to the environment. In this case, both firms would be better off than when consumers underestimate the quality of the eco-label product and overestimate that of the health-labeled product. 
In order to develop our pollution analysis, we assume that environmental quality $q_{i}$ of a product is simply measured by the abatement effort of the firm $i$. Global abatement is then defined $A=q d_{N L}+q_{L H} d_{L H}+q_{L E} d_{L E}$. The effects of a rise in minimum quality standard $q_{L H}$ and in label differentiation $\gamma$ on abatement are shown in Figures 7.

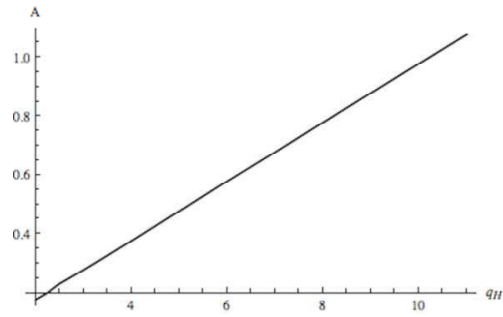

Fig 7a. Effects of a rise in $q_{L H}$

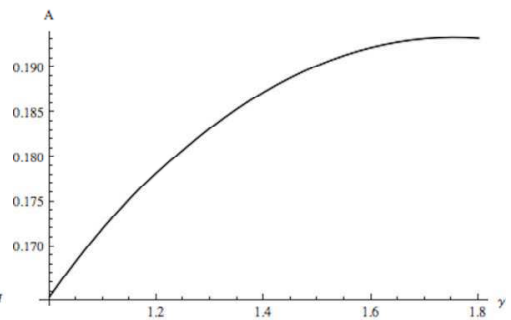

Fig $7 b$. Effects of a rise in $\gamma$

Figures 7. Abatement

In section 3 we showed that a higher standard $q_{L H}$ tends to increase the demand for the health-labeled product, to increase and then decrease the demand for the eco-labeled product and to the decrease the demand for the unlabeled product. Thus, higher standard $q_{L H}$ leads to higher abatement. On the other hand, a higher $\gamma$ induces a higher abatement effort of firm $\mathrm{E}$ but reduces its market share to the benefit of firm $\mathrm{H}$, and to the benefit or the expense of firm $\mathrm{U}$ according to the value of $\mu$. Hence, a rise in $\gamma$ has a bell-shaped effect on global abatement. ${ }^{17}$ Therefore, the NGO should submit the highest achievable health label $\hat{q}_{L H}=\bar{q}$ and an eco-label just as exacting, such as $\hat{\gamma}=1$, since eco-label requirement cannot be higher than $\bar{q} \cdot{ }^{18}$ It is worth noting that if the NGO was only in charge of the eco-label, while Firm $\mathrm{H}$ would choose its own quality, then it would set $\hat{\gamma}=1$, since Firm H would set $q_{L H}^{*}=\bar{q}$.

In the symmetric case, abatement is defined by:

$$
\begin{aligned}
& A^{I}=\frac{1}{16}(4 \bar{\theta} \bar{q}-4(\bar{\theta}-4) \underline{q}-11 \tau+\phi) \text { if } \bar{\theta} \leq \bar{\theta}_{0} \\
& A^{I I}=\frac{1}{20}(2(2 \bar{\theta}+9) \bar{q}-2(2 \bar{\theta}-1) \underline{q}+3 \tau-2 \psi) \text { if } \bar{\theta} \geq \bar{\theta}_{0}
\end{aligned}
$$

It is an increasing function of $\bar{q}$. For some values of $\bar{q}$, NGO policy could lead to a duopoly since the demand for the unlabeled product decreases with $q_{L H}$. In this case, firms $\mathrm{H}$ and $\mathrm{E}$ compete in a horizontally differentiated market and abatement is simply defined by $\bar{q}$.

Faced with consumer misperception of the quality of eco-labeled product, the NGO's label policy could lead to the eviction of the unlabeled product but also that of the ecolabeled product. Accordingly, the worst environmental quality has no chance of remaining in the market when labels are indirectly introduced by an NGO or directly

${ }^{17}$ Simulations show that $\hat{\gamma}$ maximizing abatement tends to decrease with $q_{L H}$. For instance, when $\bar{\theta}=2, \tau=1 \quad q_{N L}=1$ and $\mu=1 / 2$, we have $\hat{\gamma}=1.76$ if $q_{L H}=2, \hat{\gamma}=1.26$ if $\hat{q}_{L H}=6$, and $\hat{\gamma}=1.16$ if $\hat{q}_{L H}=10$

${ }^{18}$ Simulations show that abatement grows faster with $q_{L H}$ than with $\gamma$. As a consequence, setting $\hat{\gamma}=1$ is preferable to set $\hat{\gamma}>1$ and $q_{L H}=\bar{q} / \hat{\gamma}$. 
introduced by the firms. Furthermore, the greenest quality could be driven out by the second best one.

\subsection{Public labels}

The regulator's role consists of proposing labels that enhance global welfare in order to reach a second best optimum. Welfare is defined as the sum of consumers' surplus, firms' profits and the reduction in environmental damage:

$$
W=\sum_{i} C S_{i}+\sum_{i} \pi_{i}+\delta A
$$

with $C S_{i}$ the surplus of consumers purchasing the quality $q_{i}^{19}, \pi_{i}$ firm $i$ 's profit ( $i=N L, H$, $E), A$ the abatement and $\delta$ the marginal environmental damage. Figures 8 gather graphs showing the effects of a rise in minimum quality standard $q_{L H}$ and in label differentiation $\gamma$ on welfare components other than abatement (see Figures 7).

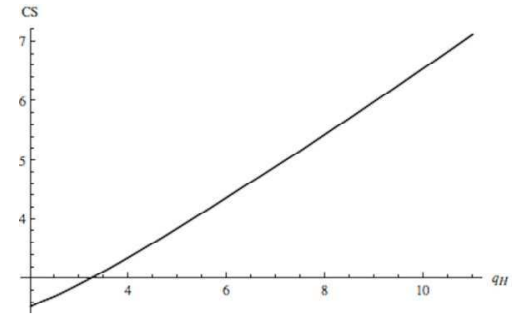

Fig. 8a. Effects of $q_{H}$ on CS

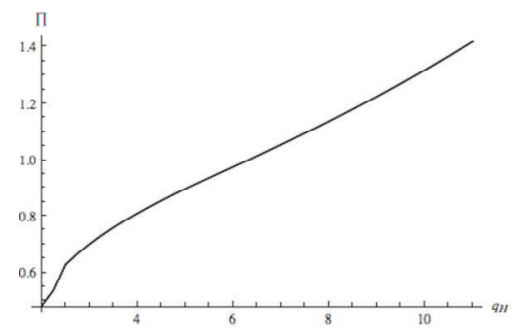

Fig. 8c. Effects of $q_{H}$ on $\Pi$

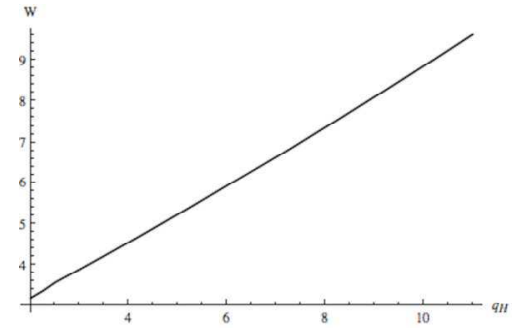

Fig. 8e. Effects of $q_{H}$ on W

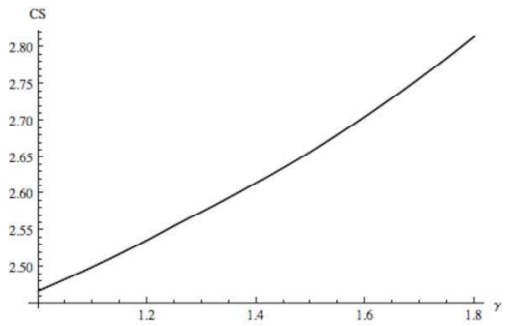

Fig. 8b. Effects of $\gamma$ on CS

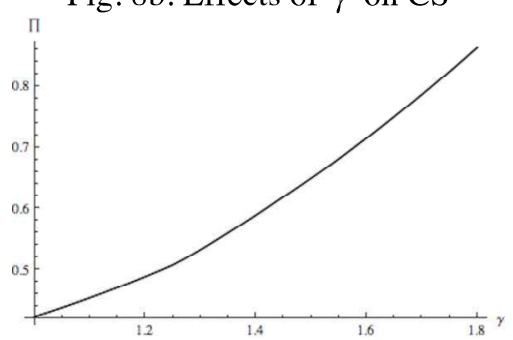

Fig. 8d. Effects of $\gamma$ on $\Pi$

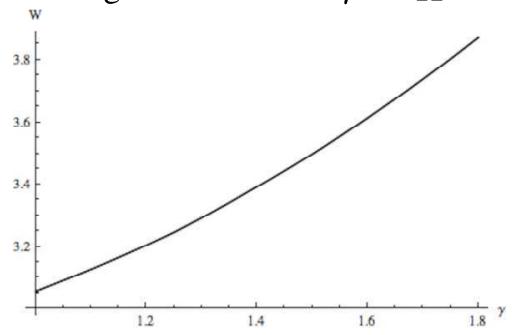

Fig. 8f. Effects of $\gamma$ on $\mathrm{W}$

Figures 8 . Welfare components

Figures 8 show that a stricter heath label will enhance welfare. A rise in $q_{L H}$ increases consumer surplus. Previous analysis highlighted that a higher standard generates higher demand for the health-labeled product and also for the eco-labeled

19 With $\quad C S_{N L}=\int_{0}^{\hat{\lambda}} \int_{\bar{\theta}-1}^{\hat{\theta}_{H}(x)} u_{N L}(\theta, \lambda) d \theta d x+\int_{\hat{\lambda}}^{1} \int_{\bar{\theta}-1}^{\hat{\theta}_{E}(x)} u_{N L}(\theta, \lambda) d \theta d x, \quad C S_{L H}=\int_{0}^{\hat{\lambda}} \int_{\hat{\theta}_{I I}(x)}^{\bar{\theta}} u_{L H}(\theta, \lambda) d \theta d x \quad$ and $C S_{L E}=\int_{\hat{\lambda}}^{1} \int_{\hat{\theta}_{E}(x)}^{\bar{\theta}} u_{L E}(\theta, \lambda) d \theta d x$ when $\bar{\theta} \leq \bar{\theta}_{0}$ 
product when $q_{L H}$ remains lower than a given threshold, to the expense of the demand for the unlabeled product. Consumer surplus follows the same develoment: surplus of consumers of health labeled and eco-labeled products increase with $q_{L H}$ (if $q_{L H}$ is not too high $)^{20}$ whereas surplus of consumers of the unlabeled product decreases. Notwithstanding this fall, the total surplus is favored by a more stringent standard. A rise in $q_{L H}$ tends to increase global profits too. As shown in previous sections, firm $\mathrm{H}$ allways benefits from this change, firm E profits from a higher quality too as long as $q_{L H}$ is not too high, and firm U suffers from such a change. In spite of this profit loss, the global profit tend to rise with $q_{L H}$. Finally, the stricter the minimum standard is, the higher the global abatement will be. Accordingly, welfare will undoubtly benefit from a more stringent standard. All in all, the regulator objective meets that of the NGO, both willing the highest possible label.

The effects of a rise in eco-label requirements are almost similar. Indeed, as seen previously, a higher $\gamma$ tends to raise global profit and can, below a given threshold, promote abatement. It enhances global consumer surplus when perceived quality is not too close to $q_{L H}{ }^{21}$ : surplus of consumers of the eco-labeled product and the unlabeled product decreases while that of consumers of the health labeled product grows, driving total surplus up. These effects on welfare components will be welfare increasing. The regulator objective is then to set the highest possible eco-label.

The optimal public label policy consists of the highest achievable health label $q_{L H}^{o}=\bar{q}$ and the just as exacting eco-label, $\gamma^{o}=1 .^{22}$ As a consequence, public policy can exclude the unlabeled product and lead to a green duopoly. In this case, welfare is simply defined by $W^{\circ}=r-\tau / 4+(\bar{\theta}+\delta-3 / 2) \bar{q}$ and it rises with $\bar{q}$ when $\bar{\theta}$ and $\delta$ are not too low.

When consumers have difficulty assessing the environmental quality of products, in spite of the existence of various labels signaling various levels of quality, the regulator must set such stringent voluntary labels in order to reach the second best optimum, that they could become compulsory minimum standards by driving the unlabeled product out of the market. In the second best world, the public eco-label should guarantee the greenest product.

\section{Conclusion}

Eco-labeling is the best way to inform consumers on the environmental quality of goods, the production process and the quality of product's components being hidden attributes. However, label profusion can blur information provided by labels. That may entail consumer confusion such that they cannot know which label is environmentally better than another. As a consequence, although they really perceive that a label is a sign of environmental quality, they will choose a label according to the image it conveys, rather than intrinsic quality it guarantees.

\footnotetext{
${ }^{20}$ When $\bar{\theta}=2, \tau=1, \gamma=1.2$ and $r=2, C S_{E}$ is maximal for $q_{L H}=6$

${ }^{21}$ For $\mu \leq 0.35$, a rise in $\gamma$ has a U-Shaped effect on the consumer surplus.

${ }^{22}$ The ensuing welfare is given in Appendix A3. As abatement, welfare grows faster with $q_{L H}$ than with $\gamma$. As a consequence, setting $\gamma^{\circ}=1$ is preferable to set $\gamma^{\circ}>1$ and $q_{L H}=\bar{q} / \gamma^{\circ}$.
} 
In this article, we translate consumer confusion by the assumption that labeled and unlabeled products are vertically differentiated, but that labeled products are only horizontally differentiated from consumers' points of view, whereas their real environmental qualities differ. Within this original framework, we show that the firm providing the greenest quality is weakened by consumer confusion, which prevents it to make the most of the consumer willingness to pay environmental quality. Paradoxically, the stricter the eco-label is, the more it risks losing market shares to the benefit of its closest competitor, which sell the health labeled product.

Furthermore, whatever the certifying organization - the firms themselves, an NGO or the regulator - label policy lead to high fall in the market share of the unlabeled product or even to its expulsion. Indeed, a stricter health label favors both firms selling labeled products by attracting more consumers at the expense of the unlabeled product. More precisely, the labeling policies are the following:

- In the case of private labels, firms choose the same environmental quality and, whereas an eco-label is not greener than a health label, they stamp different labels on products in order to attract the most consumers possible. Their strategy aims to provide high environmental quality in order to weaken, even oust, their competitor.

- In the case of labeling by an NGO or the regulator, the goals of pollution reduction and of welfare improving both require the exclusion, or at least a low market share, of the unlabeled product. This is achieved through the same highest possible environmental quality requirement for both labels, since stricter standard enhances welfare through an improvement of the consumer surplus, a rise in the global profit and a higher abatement effort.

Accordingly, when consumers cannot precisely ascertain the environmental quality of labeled products, product labeling entails high environmental quality and the firm providing the unlabeled product finds it very difficult to hold in the market. The regulator objective meets that of the NGO, both desiring the highest possible standard, i.e. maximal abatement. It is in the interest of the regulator, the NGO and the green firms to produce two apparently different labels, although the environmental quality of both labeled products are the same. A combined labeling strategy of a firm, an NGO or a regulator, providing a private label in competition with a NGO's or public label, would therefore provide the same result. This strategy allows them to attract consumers by differentiating between the products.

The main limit of our model is that global demand is not affected by prices and product quality, only demand allocation between products changes according to firm and certifier strategies. This assumption is usually adopted in horizontal or double differentiation models. However, our model would undoubtedly gain from being generalized to the case of a partially covered market. This would avoid pointing to the outcome that a labeled product can corner the market with very high qualities and prices without discouraging consumers to buy them. Moreover, the effects of labeling policies on the abatement effort of firms would be subtler, total pollution may be influenced by global consumption. Such an extension requires however resolving technical difficulties, insofar as our current model itself cannot be analytically solved. This will soon be subject to further research. 


\section{Appendix}

\section{A1. Symmetric Equilibrium}

In the first case $\left(p_{L}-p_{N L} \geq(\bar{\theta}-1) \Delta q\right)$, maximization of profit (8) with demand functions (5a) and (5b) leads to following first order conditions (FOC):

$$
\begin{aligned}
& \left.\frac{\partial \pi_{N L}^{I}}{\partial p_{N L}}\right|_{\substack{p_{L E}=p_{L} \\
p_{L H}=p_{L}}}=\frac{4 p_{L}-8 p_{N L}+4\left(\bar{\theta} q_{N L}-(\bar{\theta}-1) q_{L}\right)+\tau}{4 \Delta q}=0 \\
& \left.\frac{\partial \pi_{L j}^{I}}{p_{L j}}\right|_{\substack{p_{L E}=p_{L} \\
p_{L H}=p_{L}}}=\frac{1}{8 \tau \Delta q}\left[4 p_{L}^{2}-2 p_{L}\left(2 p_{N L}+2(\bar{\theta}+1) q_{L}-2 \bar{\theta} q_{N L}\right)+4 p_{N L}\left(q_{L}+\tau\right)\right. \\
& \left.+4 \bar{\theta} \Delta q\left(q_{L}+\tau\right)+2 \tau q_{L}-\tau^{2}\right]=0
\end{aligned}
$$

This system of equations has two candidates for the equilibrium, but only solution $\left(p_{N L}^{I}, p_{L}^{I}\right)$ described by equations (9) and (10) fulfills the following second order conditions (SOC):

$$
\begin{aligned}
& \frac{\partial^{2} \pi_{N L}^{I}}{\partial p_{N L}^{2}}=-\frac{2}{\Delta q}<0 \\
& \left.\frac{\partial^{2} \pi_{L j}^{I}}{p_{L j}^{2}}\right|_{p_{i}=p_{i}^{I}}=\frac{25 \tau-4 \bar{\theta} \Delta q-5 \Phi}{32 \tau \Delta q}<0
\end{aligned}
$$

The second SOC is fulfilled since we can easily show that $(25 \tau-4 \bar{\theta} \Delta q)^{2}$ is lower than $25 \phi^{2} .\left(p_{N L}^{I}, p_{L}^{I}\right)$ also satisfies the non-deviation conditions since $\pi_{N L}^{I}\left(p_{N L}, p_{L}^{I}\right)$ takes its maximum in $p_{N L}^{I}$ and $\pi_{L}^{I}\left(p_{N L}^{I}, p_{L}\right)$ takes its maximum in $p_{L}^{I}$. Finally, $\pi_{N L}^{I}\left(p_{N L}^{I}, p_{L}^{I}\right)$ is positive when $\Delta q<\left[(11-3 \bar{\theta}) \tau+\sqrt{97-54 \bar{\theta}+9 \bar{\theta}^{2}}\right] /(\bar{\theta}-2) \quad$ and $\quad \pi_{L}^{I}\left(p_{N L}^{I}, p_{L}^{I}\right) \quad$ is always positive when $\tau \in] 0,(\bar{\theta}-1) \Delta q]$.

In the second case $\left(p_{L}-p_{N L} \leq(\bar{\theta}-1) \Delta q\right)$, maximization of profit (8) with demand functions (6a) and (6b) leads to following FOC:

$$
\begin{aligned}
& \left.\frac{\partial \pi_{N L}^{I I}}{\partial p_{N L}}\right|_{\substack{p_{L E}=p_{L} \\
p_{L H}=p_{L}}}=\frac{\left(2 p_{L}-2 p_{N L}-2(\bar{\theta}-1) \Delta q+\tau\right)\left(2 p_{L}-6 p_{N L}-2(\bar{\theta}-1) \Delta q+\tau\right)}{4 \tau \Delta q}=0 \\
& \left.\frac{\partial \pi_{L j}^{I I}}{p_{L j}}\right|_{\substack{p_{L E}=p_{L} \\
p_{L H}=p_{L}}}=\frac{1}{2}-\frac{\left(2 p_{L}-2 p_{N L}-2(\bar{\theta}-1) \Delta q+\tau\right)^{2}}{8 \tau \Delta q}-\frac{\left(p_{L}-q_{L}\right)\left(2 p_{L}-2 p_{N L}-2(\bar{\theta}-2) \Delta q+\tau\right)}{4 \tau \Delta q}=0
\end{aligned}
$$

When $d_{N L}^{I I}>0$, (A5) implies that $2 p_{L}-6 p_{N L}-2(\bar{\theta}-1) \Delta q+\tau=0$. The system of FOC has two candidates for the equilibrium, of which only solution $\left(p_{N L}^{I I}, p_{L}^{I I}\right)$ described by equations (11) and (12) fulfills the following SOC:

$$
\begin{aligned}
& \left.\frac{\partial^{2} \pi_{N L}^{I}}{\partial p_{N L}^{2}}\right|_{p_{i}=p_{i}^{I I}}=-\frac{3(\tau-(2 \bar{\theta}-1) \Delta q+\psi)}{10 \tau \Delta q}<0 \\
& \left.\frac{\partial^{2} \pi_{L j}^{I}}{p_{L j}^{2}}\right|_{p_{i}=p_{i}^{I}}=-\frac{\tau+(51-2 \bar{\theta}) \Delta q+11 \psi}{80 \tau \Delta q}<0
\end{aligned}
$$


SOC (A7) is fulfilled if $\psi^{2}$ is higher than $((2 \bar{\theta}-1) \Delta q-\tau)^{2}$, which is true when $3 \tau>2(\bar{\theta}-2) \Delta q$. SOC (A8) is fulfilled when $\bar{\theta}<25.5$. $\left(p_{N L}^{I I}, p_{L}^{I I}\right)$ also satisfies the non-deviation conditions since $\pi_{N L}^{I I}\left(p_{N L}, p_{L}^{I I}\right)$ takes its maximum in $p_{N L}^{I I}$ and $\pi_{L}^{I I}\left(p_{N L}^{I I}, p_{L}\right)$ takes its maximum in $p_{L}^{I I}$. Finally, $\pi_{N L}^{I I}\left(p_{N L}^{I I}, p_{L}^{I I}\right)$ is positive when $3 \tau>2(\bar{\theta}-2) \Delta q$ and $\pi_{L}^{I I}\left(p_{N L}^{I I}, p_{L}^{I I}\right)$ is positive when $\left.\tau \in] \frac{1}{2}(4 \bar{\theta}+1-3 \sqrt{8 \bar{\theta}-7}) \Delta q,(\bar{\theta}-1) \Delta q\right]$.

\section{A2. Asymmetric Equilibrium}

When $q_{L E}>q_{L H}$, unfortunately, no analytical candidates to Nash equilibrium can be found using the FOC. We also turn to simulations for parameters $\bar{\theta}, \gamma, q_{L H}, q_{N L}, \tau$ and $\mu$, setting the fixed costs $k_{i}$ to zero $(i=N L, L H, L E)$. More precisely, we set five of the six parameters and we assess the Nash equilibrium for each admissible value of the sixth parameter, using the Mathematica software. In order to do this, we follow the procedure below (programs can be obtained on request from the author):

(i) We calculate the three FOC, such as $\partial \pi_{i} / \partial p_{i}=0(i=N L, L H, L E)$, in the three cases illustrated in Figures 2. In Case I, $\hat{\theta}_{H}(0) \geq \bar{\theta}-1$ and $\hat{\theta}_{E}(1) \geq \bar{\theta}-1$ and demand functions are defined by $d_{i}^{I}$ (i=NL, LH, LE). In case II, $\hat{\theta}_{H}(0)<\bar{\theta}-1$ and $\hat{\theta}_{E}(1) \geq \bar{\theta}-1$ and demand functions are defined by $d_{L H}^{I I}, d_{L E}^{I}$ and $d_{N L}=1-d_{L H}^{I I}-d_{L E}^{I}$. In case III, $\hat{\theta}_{H}(0)<\bar{\theta}-1$ and $\hat{\theta}_{E}(1)<\bar{\theta}-1$ and demand functions are defined by $d_{L H}^{I I}, d_{L E}^{I I}$ and $d_{N L}=1-d_{L H}^{I I}-d_{L E}^{I I}$.

(ii) We calculate the candidates for the Nash equilibrium in the three cases, using function FindRoot allowing to numerically find local roots of the FOC, starting from the symmetric Nash equilibrium $\left(p_{N L}^{I}, p_{L}^{I}\right)$.

(iii) Using these prices, we evaluate $\hat{\theta}_{H}(0)$ and $\hat{\theta}_{E}(1)$ and we select adequate equilibrium $\left(p_{N L}^{*}, p_{L H}^{*}, p_{L E}^{*}\right)$ according to the values of $\hat{\theta}_{H}(0)$ and $\hat{\theta}_{E}(1)$ with respect to $\bar{\theta}-1$.

(iv) We evaluate demands and profits at the equilibrium.

(v) We check that the SOC are fulfilled.

(vi) We construct tables of solutions for prices, demands and profits according to the varying parameter.

(vii) Using function ListLinePlot, we plot prices, demands and profits according to the varying parameter.

\section{A3. Welfare at the Symmetric Equilibrium}

In the case where $\bar{\theta} \leq \bar{\theta}_{0}$, welfare is given by:

$$
\begin{aligned}
W^{I}= & r+\frac{\left(7 \bar{\theta}^{2}-20 \bar{\theta}+32\right) \bar{q}-\left(\bar{\theta}^{2}+4 \bar{\theta}+8\right) \underline{q}}{16} \\
& -\frac{\left(37 \bar{q}-59 q_{N L}\right) \tau+4 \Delta q((\bar{\theta}-12) \underline{q}+(20-7 \bar{\theta}) \bar{q})}{256 \Delta q^{2}} \phi \\
& +\frac{1121 \bar{q}-1791 \underline{q}}{768 \Delta q^{2}} \tau^{2}+\frac{(110-39 \bar{\theta}) \bar{q}+(5 \bar{\theta}-66) \underline{q}}{32 \Delta q} \tau \\
& -k_{L E}-k_{L H}+\delta\left[\frac{4 \bar{\theta} \Delta q-11 \tau+\phi}{16}+\underline{q}\right]
\end{aligned}
$$

In the case where $\bar{\theta} \geq \bar{\theta}_{0}$, welfare is defined by: 


$$
\begin{aligned}
W^{I I}= & r+\frac{\left(48 \bar{\theta}^{2}-58 \bar{\theta}+247\right) \bar{q}+\left(32 \bar{\theta}^{2}+178 \bar{\theta}-727\right) \underline{q}}{250}-\frac{\Delta q^{2}\left(12 \bar{\theta}^{3}-88 \bar{\theta}^{2}+289 \bar{\theta}-349\right)}{250 t} \\
& +\frac{(22 \underline{q}-7 \bar{q}) \tau^{2}-2 \Delta q(3(7 \bar{\theta}-1) \bar{q}+(19 \bar{\theta}-92) \underline{q}) \tau+2 \Delta q^{3}\left(6 \bar{\theta}^{2}-11 \bar{\theta}-11\right)}{500 \tau \Delta q^{2}} \psi \\
& +\frac{83 \bar{q}-243 \underline{q}}{3000 \Delta q^{2}} \tau^{2}+\frac{(414-28 \bar{\theta}) \bar{q}+(168 \bar{\theta}-1009) \underline{q}}{500 \Delta q} \tau \\
& -k_{L E}-k_{L H}+\delta \frac{2(2 \bar{\theta}+9) \bar{q}-2(2 \bar{\theta}-1) \underline{q}+3 \tau-2 \psi}{16}
\end{aligned}
$$

A4. Effects of a rise in quality perception

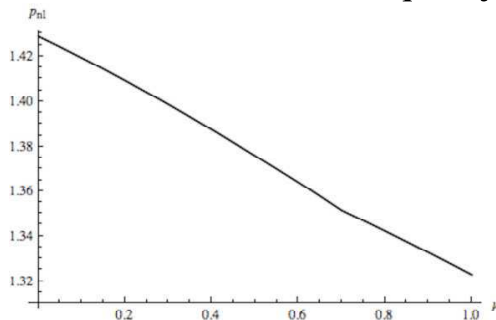

Fig. A1a. $p_{N L}$

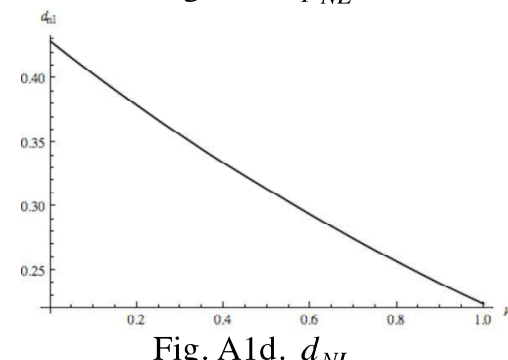

Fig. A1d. $d_{N L}$

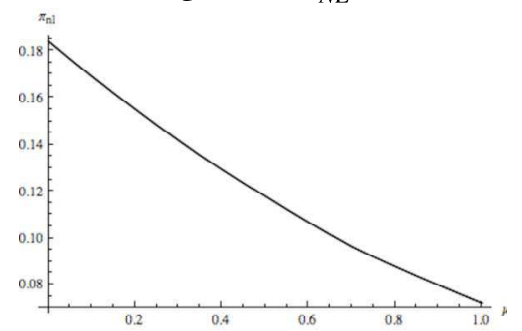

Fig. A1g. $\pi_{N L}$

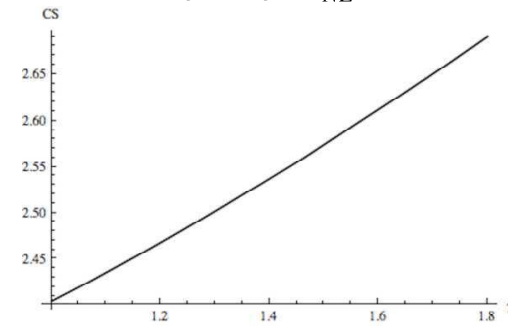

Fig. A1j. CS

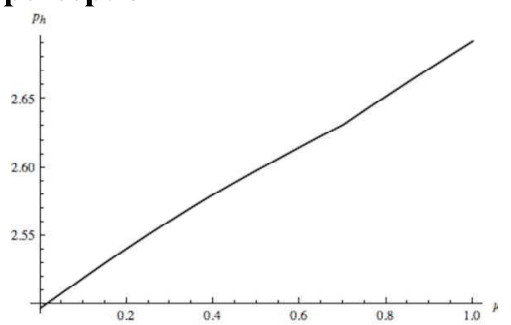

Fig. A1b. $p_{L H}$

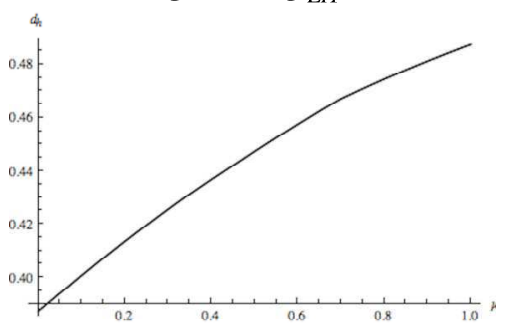

Fig. Ale. $d_{L H}$

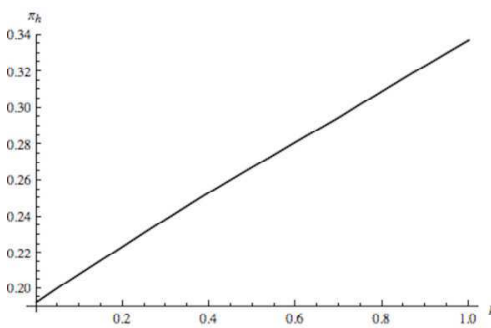

Fig A1h. $\pi_{L H}$

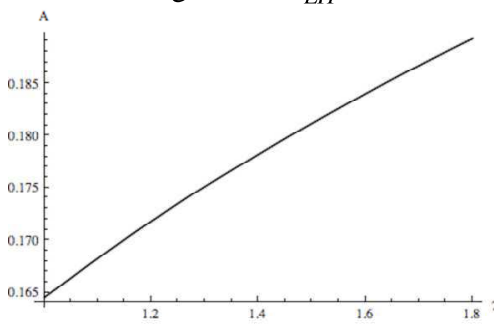

Fig. A1g. Abatement

Figures A1. Effects of a rise in $\mu$

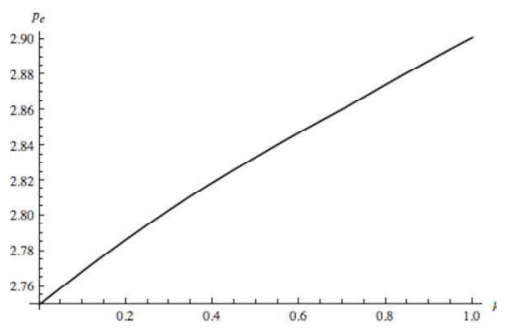

Fig. A1c. $p_{L E}$

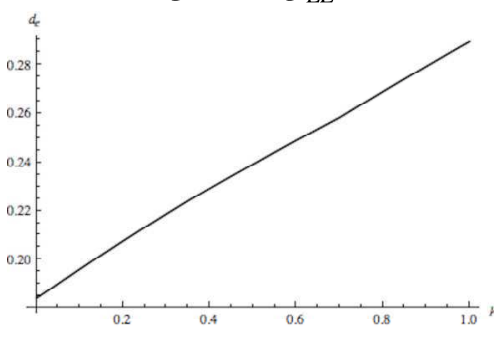

Fig. A1f. $d_{L E}$

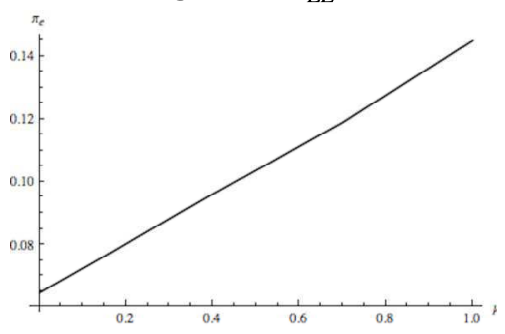

Fig A1i. $\pi_{L E}$

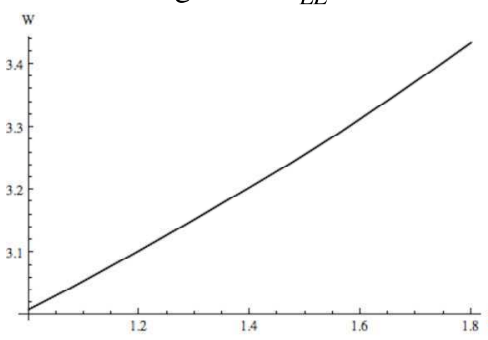

Fig. A1g. Welfare 


\section{References}

Amacher G., Koskela E., Ollikainen M. (2004), Environmental quality competition and eco-labeling, Journal of Environmental Economics and Management 47, 284-306.

Andreoni, J. (1990), Impure Altruism and Donations to public-Goods - a theory of Warm-Glow Giving, Economics Journal, 100 (401), 464-477.

Arkesteijn K., Oerlemans L. (2005), The early adoption of green power by Dutch households: An empirical exploration of factors influencing the early adoption of green electricity for domestic purposes, Energy Policy, 33, 183-196.

D'Aspremont, C., Gabszewicz, J. and Thisse, J. F. (1979). On Hotelling's Stability in Competition, Econometrica, 47, 1145-1151.

Ben Youssef A., Abderrazak C. (2009), Multiplicity of Eco-Labels, Competition and the environment, Journal of Agricultural \& Food Industrial Organization 7, special issue: Quality Promotion through Eco-labeling.

Ben Youssef A., Lahmandi-Ayed R. (2008), Eco-labelling, Competition and Environment: Endogenization of Labelling Criteria, Environmental and Resource Economics, 41, 133-154.

Boyer M., Mahenc P., Moreaux M. (2006), Environmental Protection, Consumers Awareness, Product Characteristics and Market Power, in Boyer, M., Hiriart, Y. and D. Martimort (editors), Frontiers in the Economics of Environmental Regulation and Liability, 121-152.

Bottega L. de Freitas J. (2009), Public, private and nonpofit regulation for environmental quality, Journal of Economics \& Management Strategy, 18(1), 105123.

Brécard, D., Hlaimi B., Lucas S., Salladarré F., Perraudeau Y. (2009), Determinants of demand for green products: An application to eco-label demand for fish in Europe, Ecological Economics, 69, 115-125.

Canoy M., Peitz M. (1997), The differentiation triangle, The Journal of Industrial Economics, XLV, 305-328.

Clemenz G. (2010), Eco-Labeling and Horizontal Product Differentiation, Environmental and Resource Economics 45, 481-497.

Conrad K. (2005), Price Competition and Product Differentiation when Consumers Care for the Environment", Environmental and Resource Economics, 31, 1-19.

Ek K., Söderholm P. (2008), Norms and economics motivation in the Swedish green electricity market, Ecological Economics, 68(1-2), 169-182.

Eriksson C. (2004), Can green consumerism replace environmental regulation? A differentiated product example, Resource and Energy Economics, 26, 281-293.

European Commission (2009), Europeans' attitudes towards the issue of sustainable consumption and production, Flash Eurobarometer, 256.

European Commission, 2008. Attitudes of Europeans citizens towards the environment. Eurobarometer 295.

Grankvist, G., Biel, A. (2001). The importance of beliefs, purchase criteria and habits for the choice of environmentally friendly food products, Journal of Environmental Psychology, 21, 405- 410.

Grankvist, G., Biel, A. (2007). Predictor of purchase of eco-labeled food products: a panel study, Food Quality and Preference 18(4), 701-708

Ibanez L., Grolleau G. (2008), Can Ecolabeling Schemes Preserve the Environment?, Environmental and Resource Economics, 40(2), 233-249. 
Kotchen, M. J. and Moore, M. R. (2007), Private provision of environmental public goods: Household participation in green-electricity programs, Journal of Environmental Economics and Management, 53, 1-16.

Loureiro M. L., Lotade J. (2005). Do fair trade and eco-labels in coffee wake up the consumer conscience?, Ecological Economics, 53(1), 129-138.

Mahenc, P. (2008), Signaling the environmental performance of polluting products to green consumers, International Journal of Industrial Organization, 26, 59-68.

Mahenc, P. (2009), Wasteful labeling, Journal of Agricultural \& Food Industrial Organization 7(2), article 6.

McCluskey J. J., Loureiro M. L (2003) Consumer Preferences and Willingness to Pay for Food Labeling: A Discussion of Empirical Studies, Journal of Food Distribution Research, 34(3), 95-102.

Mussa, M., Rosen, S. (1978), Monopoly and Product Quality, Journal of Economic Theory, 18, 301-317.

Neven D., Thisse J. F. (1990), On Quality and Variety Competition, in J.J. Gabszewicz, J.-F. Richard and L. Wolsey, eds., Economic Decision Making: Games, Econometrics and Optimization. Contributions in Honour of J. Drèze. Amsterdam, North-Holland, 175-199.

OECD, 2005. Effects of Eco-labelling Schemes: Compilation of Recent Studies. Joint Working Party on Trade and Environment, COM/ENV/TD(2004)34/FINAL.

Schumacher I. (2010), Ecolabeling, consumers' preferences and taxation, Ecological Economics 69, 2202-2212.

Torgler, B. and Garcia-Valinãs, M. A. (2007), The determinants of individuals Attitudes Towards Preventing Environmental Damage, Ecological Economics, 63, 536-552. 